\title{
Regímenes sectoriales, productividad y competitividad internacional
}

\section{Jorge Katz}

Director. División de

Desarrollo Productivo

y Empresarial, CEPAL

jkatz@eclac.cl

\section{Giovanni Stumpo}

Unidad Conjunta CEPAL/ONUDI

de Desarrollo Industrial

y Tecnológico, CEPAL

gstumpo@eclac.cl
El presente artículo busca examinar diversos aspectos mesoeconómicos y microeconómicos relacionados con la productividad y la competitividad internacional en el contexto del nuevo modelo económico latinoamericano. Estos aspectos contribuyen de manera importante a explicar por qué dichas variables no han evolucionado satisfactoriamente en los distintos países y sectores de actividad, y por qué una lectura estrictamente macroeconómica bloquea la capacidad de comprensión de los cambios productivos, tecnológicos e institucionales que están ocurriendo en la sociedad, así como la identificación de una agenda de políticas públicas útil para mejorar los alcances de la transformación en marcha.

En este proceso se han ido consolidando nuevos patrones de comportamiento microeconómico en los que los bienes de capital e insumos intermedios importados han ido desplazando a la producción local y a los esfuerzos tecnológicos locales asociados a su fabricación. A partir de ello se ha ido conformando un nuevo modelo de organización de la producción, más articulado con el exterior que en el pasado. 


\section{I}

\section{Introducción}

Siguiendo el camino de la "teorización apreciativa" (Richard Nelson, 1997), la CEPAL ha descrito en varios estudios recientes diversos rasgos estilizados del nuevo modelo de organización social y de producción que fue tomando forma en los países de América Latina y el Caribe tras las reformas estructurales procompetitivas de los años noventa. ${ }^{1}$

Se señala en dichos estudios que la transición desde un paradigma de desarrollo "endodirigido", liderado por el Estado, hacia otro más abierto y desregulado —en el que la "mano invisible" adquiere un papel protagónico y orienta la asignación de recursosha ido induciendo en los diversos países de la región el desarrollo de nuevos patrones de especialización productiva y de inserción en los mercados mundiales de bienes y servicios. Esto ha ocurrido en el marco de un episodio de largo plazo de "destrucción creativa" de naturaleza schumpeteriana, en el que un cierto modelo de organización de la producción y de comportamiento institucional y tecnológico fue desplazado gradualmente por otro, mediante la acción conjunta e interdependiente de fuerzas económicas, tecnológicas e institucionales. La interdependencia de lo macroeconómico y lo microeconómico aparece como un tema central del escenario que se pretende describir. La macroeconomía -incierta, sujeta a fluctuaciones cíclicas en buena medida determinadas por el comportamiento errático de los mercados de capital internacionales- induce formas "defensivas" de comportamiento microeconómico, las que a su vez retroalimentan el cuadro de escaso dinamismo global con mejoras de productividad y competitividad internacional inferiores a las que registran otras partes del mundo. Es esto lo que impide a los países de la región cerrar la brecha relativa de productividad e ingresos que los aleja del mundo industrializado. En una macroeconomía que no acaba de superar su alto grado de incertidumbre y riesgo, las mejoras de productividad en la microeconomía se logran más a través de la expulsión de mano de obra en plantas fabriles relativamente "viejas" que mediante programas importantes de inversión y moder-

\footnotetext{
${ }^{1}$ Stallings y Peres (2000), World Development (2000), Katz (2000), Moguillansky y Bielschowsky (2000), Weller (2000), Ffrench-Davis (1999) y Ocampo (2001).
}

nización tecnológica. Variables estrictamente económicas - como el tipo de cambio, la tasa de interés, la inversión, los salarios reales- interactúan con otras de carácter institucional y tecnológico - como los derechos de propiedad, el mayor o menor grado de imperfección de los mercados de factores, el nivel de capacidad tecnológica alcanzado por los distintos países-, dando forma a un proceso de crecimiento de largo plazo que dista de ser satisfactorio.

Los estudios cepalinos muestran asimismo que, además de ser insatisfactorio en lo que hace a ritmos de crecimiento y eficiencia microeconómica, el nuevo modelo económico latinoamericano tampoco exhibe grandes logros en el plano de la equidad. En efecto, se caracteriza por una profunda heterogeneidad estructural, en muchos sentidos más acentuada que durante los años de la industrialización sustitutiva de importaciones. Algunas actividades económicas, regiones o aun agentes económicos individuales dentro de cada sector productivo, han logrado adaptarse mejor — por la imperfección de los mercados de factores, las asimetrías de información, o una mayor capacidad de cabildeo político- a las nuevas reglas del juego, en tanto que otros no han podido hacerlo. Los primeros han capitalizado en su beneficio las nuevas oportunidades abiertas por el cambio en el régimen global de incentivos prevaleciente en la sociedad, en tanto que los segundos han tendido a decaer en el tiempo, perdiendo participación relativa dentro de la estructura de producción, o lisa y llanamente han ido desapareciendo de ella. El proceso de transformación estructural en marcha está también marcado por un fuerte aumento en el grado de concentración económica y por la consolidación de nuevas posiciones de monopolio dentro del aparato productivo, en un contexto en que el Estado ha perdido poder regulatorio y capacidad de intervención en defensa del interés público.

El propósito de este trabajo es el de examinar diversos aspectos mesoeconómicos y microeconómicos relacionados con la productividad y la competitividad internacional. Argumentaremos aquí que unos y otros cumplen un papel importante - y con frecuencia olvidado- en la explicación de por qué dichas variables no han evolucionado satisfactoriamente en los distintos países y sectores de actividad, y por qué una lectura estrictamente macroeconómica bloquea nuestra 
capacidad de comprender los cambios productivos, tecnológicos e institucionales que están ocurriendo en la sociedad, y también la identificación de una agenda de políticas públicas útil para mejorar los alcances de la transformación en marcha. Si el diagnóstico es exclusivamente macroeconómico, poco puede sorprendernos que la agenda dominante se limite a recomendar "más de lo mismo", esto es, profundizar la apertura comercial, continuar desregulando mercados y terminar de privatizar todo lo que aún no ha sido privatizado.

El artículo está dividido en cuatro secciones. Luego de la presente introducción, en la sección II se compara el desempeño global que exhibió la región durante la etapa de crecimiento endodirigido (19401980) con el que alcanzó en el decenio de 1990, cuando los países latinoamericanos optaron por una estrategia de crecimiento más abierta a la competencia externa, más desregulada y con menos participación del Estado en actividades productivas. El patrón medio, más allá de su interés como telón de fondo de la situación contemporánea, no describe bien los distintos casos nacionales; por lo tanto, una vez presentado el panorama global, pasamos a examinar las diferencias de desempeño entre países y actividades productivas, centrando nuestro análisis en indicadores de productividad del trabajo y de la competitividad revelada internacional.

En la sección III se hace un primer esfuerzo de teorización apreciativa acerca de este proceso. Nuestra lectura de él gira en torno a la noción schumpeteriana de la "destrucción creativa". Argumentamos allí que los regímenes tecnológicos y competitivos sectoriales cambian por la "muerte" y "nacimiento" de empresas, por la llegada de nuevos actores internacionales y por el aggiornamento de las instituciones, ${ }^{2}$ las tecnologías y las reglas de comportamiento competitivo de cada sector productivo. Estamos frente a un proceso de mutación estructural de largo plazo que hasta ahora la profesión está lejos de haber comprendido a cabalidad (Caballero y Hammour, 1996). En la sección IV, por último, se presentan algunas reflexiones finales sobre los procesos analizados.

\section{II}

\section{La situación contemporánea}

\section{El cuadro agregado}

Las cifras del cuadro 1 dan fundamento al gran escepticismo que reina actualmente respecto al efecto de las reformas de los años noventa destinadas a promover la competitividad. La información se condensa en cuatro dimensiones específicas: i) el comportamiento de la macroeconomía, reflejado sumariamente en la tasa de inflación de la región en su conjunto; ii) el desempeño del sector externo, resumido en tasas agregadas de crecimiento de las importaciones y exportaciones; iii) el funcionamiento del aparato productivo, representado por las tasas de crecimiento del producto interno bruto y de la productividad laboral, y iv) lo ocurrido en materia de equidad, representado por un índice de hogares pobres en el total de la población.

El patrón de luces y sombras es evidente. La región ha progresado mucho en el manejo de lo macroeconómico. La tasa de inflación, por ejemplo, muestra que el desempeño de las economías latinoamericanas mejoró considerablemente en el decenio de 1990. También los países latinoamericanos estuvieron más abiertos al comercio que en décadas anteriores. Sin embargo, la tasa de crecimiento de las importaciones fue más alta que la de las exportaciones, lo que indica que la apertura de la región al comercio fue mayor para las primeras. Esto habla de cierta vulnerabilidad en el sector externo del nuevo modelo económico latinoamericano, a la cual los gobiernos de la región están prestando hoy una atención cada vez mayor. ${ }^{3}$ Volveremos

\footnotetext{
2 El término "instituciones" es manejado por la profesión con cierta ambigüedad. Se usa tanto para identificar agencias o entidades - bancos, universidades, aduanas - como para referirse a normas de conducta o reglas de comportamiento. Así, el sistema de patentes de invención es una "institución" y también lo es la protección arancelaria. Sobre este debate, véase David (1994).

${ }^{3}$ En un estudio reciente sobre las exportaciones brasileñas, Miranda (2000) argumenta que no sólo es urgente incrementar las exportaciones, sino que probablemente también será urgente en el futuro volver a sustituir importaciones en sectores de la producción que hacen uso intensivo de insumos intermedios importados - como bienes de capital, productos electrónicos o materias primas farmacéuticas- y que concentran los grandes déficit de comercio exterior que hoy exhiben varias economías de la región. El mismo debate se da actualmente en Argentina. En muchos sentidos, recuerda las viejas discusiones cepalinas de los años cincuenta, relacionadas con la restricción externa crónica que enfrentaban varias de las economías latinoamericanas. En una sección posterior del trabajo volveremos a este tema (véase Miranda, 2000).
} 
Desempeño global latinoamericano durante la industrialización sustitutiva de importaciones y en el decenio de 1990

(Porcentajes)

\begin{tabular}{lccrr}
\hline & $1945-1980$ & $1980-1990$ & $1990-2000$ & 2000 \\
\hline Tasa anual de inflación & 20 & 400 & 170.0 & 9.2 \\
Tasa de crecimiento de las exportaciones & 2.1 & 4.4 & 9.4 & 11.1 \\
Tasa de crecimiento de las importaciones & 5.9 & -0.8 & 12.8 & 12.3 \\
Tasa de crecimiento del PIB & 5.6 & -1.8 & 3.3 & 4.3 \\
Tasa de crecimiento del PIB per cápita & 3.1 & 41 & 38 & 2.2 \\
Porcentaje de hogares pobres & 35 & 38 & 38 \\
\hline
\end{tabular}

Fuente: CEPAL, 2000.

a ella posteriormente. Por otro lado, también debemos tener presente que en los promedios que nos brinda el cuadro influyen fuertemente las cifras de México, país que en el decenio de 1990 logró duplicar sus exportaciones globales gracias a la rápida expansión de su industria maquiladora, destinada a abastecer los mercados estadounidenses de televisores, equipos de vídeo, computadores e indumentaria. ${ }^{4}$

No obstante, el desempeño global de la región aparece como menos satisfactorio, si nos remitimos a los indicadores de producción, productividad laboral y equidad distributiva, que en promedio no muestran mejoras de largo plazo, salvo con respecto a la "década perdida" de los años ochenta.

\section{Diferencias entre países}

Son pocos los países de la región que en la década de 1990 crecieron más rápido que en su etapa de industrialización sustitutiva y que mejoraron el ritmo histórico de crecimiento de su producto interno bruto. Solamente lo lograron Argentina, Bolivia y Uruguay (gráfico 1). En todos los demás el desempeño en los años noventa fue claramente peor, particularmente en las dos economías más grandes de la región —-Brasil y México-, que sólo hacia el final de la década recuperaron un mayor ritmo expansivo, aunque todavía inferior al que mostraban en los años setenta.

Un patrón parecido - de grandes diferencias de desempeño entre países - es el que emerge si consi-

\footnotetext{
${ }^{4}$ México ha pasado en pocos años de 60 mil millones de dólares de exportaciones a más de 150 mil millones; poco menos de la mitad de dicha cifra corresponde a producción de maquila destinada al mercado estadounidense. El tema suscita en la actualidad, entre los estudiosos del modelo mexicano, un debate a fondo relativo al valor agregado interno y al desarrollo de capacidades locales de ingeniería que derivan del crecimiento de la maquila (véase Buitelaar, Padilla y Urrutia,1999; Gerber, 2000; Dussel, 2000a; Cimoli 2001).
}

GRAFICO 1

\section{América Latina: Crecimiento medio del producto interno bruto, 1991-2000}

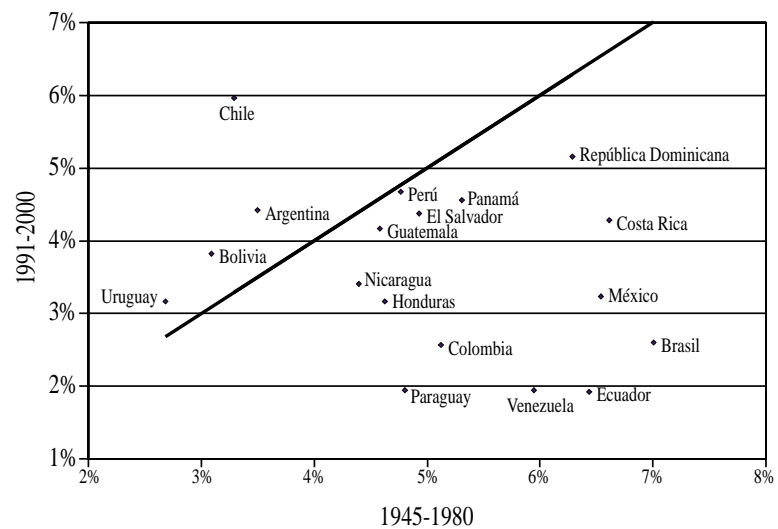

Fuente: CEPAL, 2000.

deramos indicadores de competitividad revelada internacional.

La información disponible muestra, ante todo, que la región en su conjunto no ha mejorado significativamente en lo que a penetración en los mercados mundiales se refiere. En efecto, América Latina generaba $5.57 \%$ del comercio internacional en 1985, cifra que subió sólo a $5.67 \%$ en 1998. Aun así, algunos pocos países lograron ganar participación relativa en las corrientes mundiales de comercio a lo largo del período indicado. En forma notoria ése es el caso de México, que entre ambas fechas pasó de producir $1.55 \%$ de las importaciones mundiales totales a producir $2.24 \%$ de ellas. En mucho menor medida, es también el caso de Argentina y Chile, que pasaron, respectivamente, de proporcionar el $0.37 \%$ y el $0.23 \%$ de las importaciones mundiales en 1985, a suministrar el $0.51 \%$ y el $0.32 \%$ de ellas en 1998 ; y sólo marginalmente es el caso de Costa Rica, El Salvador, Guatema- 
la, Honduras y la República Dominicana, cuya participación relativa aumentó mucho menos (cuadro 2).

En otros términos, ya sea que nuestro juicio provenga de estadísticas de producción y productividad laboral, o de indicadores de comercio, que reflejan competitividad revelada, es evidente que a nivel agregado América Latina logró escasas mejoras en los años noventa y que sólo unos pocos países de la región consiguieron superar su desempeño anterior. Además, los dos cuerpos de datos muestran que no siempre hay una buena correlación entre ambos indicadores. En México, por ejemplo, el éxito en materia de competitividad revelada contrasta marcadamente con su insatisfactorio desempeño en materia de productividad laboral (gráfico 2). El crecimiento liderado por las exportaciones no parece ser tan automático como suele suponerse en los debates contemporáneos sobre crecimiento.

CUADRO 2

América Latina y el Caribe: Participación de mercado en las importaciones mundiales, 1985-1998

\begin{tabular}{|c|c|c|c|}
\hline \multirow[t]{2}{*}{ Países } & \multicolumn{3}{|c|}{ Cuota de mercado } \\
\hline & 1985 & 1998 & Diferencia \\
\hline Argentina & 0.37 & 0.51 & 0.14 \\
\hline Chile & 0.23 & 0.32 & 0.09 \\
\hline México & 1.55 & 2.24 & 0.69 \\
\hline Costa Rica & 0.07 & 0.10 & 0.03 \\
\hline El Salvador & 0.04 & 0.05 & 0.01 \\
\hline Guatemala & 0.06 & 0.08 & 0.02 \\
\hline Honduras & 0.05 & 0.07 & 0.02 \\
\hline República Dominicana & 0.08 & 0.10 & 0.02 \\
\hline Bolivia & 0.04 & 0.02 & -0.02 \\
\hline Brasil & 1.37 & 1.01 & -0.36 \\
\hline Colombia & 0.24 & 0.24 & 0.00 \\
\hline Ecuador & 0.17 & 0.11 & -0.06 \\
\hline Paraguay & 0.03 & 0.03 & 0.00 \\
\hline Perú & 0.17 & 0.12 & -0.05 \\
\hline Uruguay & 0.07 & 0.06 & -0.01 \\
\hline Venezuela & 0.66 & 0.41 & -0.25 \\
\hline Nicaragua & 0.02 & 0.02 & 0.00 \\
\hline Barbados & 0.02 & 0.00 & -0.02 \\
\hline Cuba & 0.03 & 0.02 & -0.01 \\
\hline Haití & 0.03 & 0.01 & -0.02 \\
\hline Jamaica & 0.04 & 0.04 & 0.00 \\
\hline Trinidad y Tabago & 0.10 & 0.04 & -0.06 \\
\hline Guyana & 0.02 & 0.01 & -0.01 \\
\hline Panamá & 0.10 & 0.05 & -0.05 \\
\hline Suriname & 0.02 & 0.01 & -0.01 \\
\hline
\end{tabular}

Fuente: CAN 2000 (Análisis competitivo de los países, versión 2000), programa computacional de la Unidad de Desarrollo Industrial y Tecnológico, División de Desarrollo Productivo y Empresarial, CEPAL.
GRAFICO 2

América Latina: Productividad

laboral, 1951-1980

(Crecimiento medio del producto interno bruto por trabajador activo)

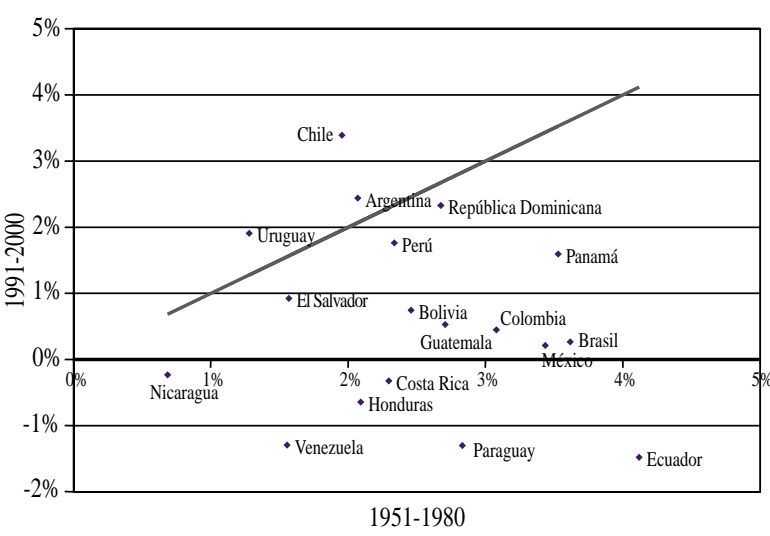

Fuente: CEPAL, 2000.

3. Patrones sectoriales de especialización productiva y de inserción en el comercio mundial: emulación (catching-up) y rezago (lagging behind) sectoriales

Las estadísticas de producción y productividad, por un lado, y las de comercio internacional, por otro, nos permiten seguir avanzando en la caracterización del fenómeno de reestructuración del aparato productivo tras las reformas estructurales recientes. Estas nos muestran con claridad que en las décadas de 1980 y 1990 se fueron consolidando en América Latina dos grandes modelos dominantes de especialización productiva y comercio.

El primero de estos modelos caracteriza a los países del Cono Sur (Chile, Argentina, Brasil) y a algunos países andinos (Colombia y Perú), y muestra un claro vuelco hacia las actividades procesadoras de recursos naturales que producen commodities industriales como aceites vegetales, celulosa y papel, hierro y acero, harina de pescado y otros. Desde el punto de vista de la organización productiva, se trata de industrias que hacen uso intensivo de recursos naturales y que producen en plantas muy automatizadas, con mucho capital y poca mano de obra. Desde la perspectiva del comercio internacional, se trata de sectores productivos en los que la demanda mundial crece despacio y la elasticidad a los precios o los ingresos es baja. Por último, desde el ángulo tecnológico, puede decirse que son industrias maduras, en las que no hay mayores esfuerzos de ingeniería de diseño con miras a nuevos productos, aunque sí los hay por mejorar 
procesos y la organización de la producción (especialmente en cuanto a transporte, frío, funcionamiento de los terminales portuarios, envases y embalajes, etc.).

Distinto es el caso de México y de varios de los países más pequeños de América Central, donde el patrón de especialización productiva ha ido acentuando gradualmente la participación relativa de industrias ensambladoras de aparatos electrónicos, de computadores y de vestuario, principalmente para el mercado estadounidense. Algunas de estas industrias han operado bajo el régimen de maquila, pese a tratarse básicamente de plantas de montaje de insumos intermedios importados (Dussel, 2000b; Buitelaar, 1999); pero todas hacen uso intensivo de mano de obra. La maquila mexicana generó más de un millón de nuevos puestos de trabajo en el decenio de 1990. Empleando tecnologías de última generación y una sofisticada logística de abastecimiento justo a tiempo de partes y componentes, así como técnicas de calidad total y otras traídas casi íntegramente desde las respectivas casas matrices, ${ }^{5}$ pero pagando salarios que son sólo una fracción —no mucho más del 10\% — del que pagan los países desarrollados; dichas plantas ensambladoras producen casi íntegramente para competir en el mercado interno de los Estados Unidos. Allí la demanda creció con mucha rapidez en los años noventa, y tanto el diseño de productos (que no se lleva a cabo en los establecimientos fabriles de la región) como las marcas de fábrica desempeñan un papel importante en un contexto de mercados imperfectamente competitivos.

El cuadro 3 nos muestra que el peso relativo del conjunto de ramas productoras de commodities (esto es, del conjunto de ramas industriales que procesan recursos naturales), por un lado, y del de alimentos, por

CUADRO 3

América Latina (seis países): Estructura del valor agregado industrial ${ }^{\mathrm{a}}$

(Composición en porcentajes)

\begin{tabular}{|c|c|c|c|c|c|c|c|c|c|c|c|c|}
\hline \multirow[b]{2}{*}{ Sectores b } & \multicolumn{4}{|c|}{ Argentina } & \multicolumn{4}{|c|}{ Brasil } & \multicolumn{4}{|c|}{ México } \\
\hline & 1970 & 1980 & 1990 & 1999 & 1970 & 1980 & 1990 & 1999 & 1970 & 1980 & 1990 & 1999 \\
\hline 01 & 13.2 & 13.4 & 8.8 & 10.8 & 16.2 & 25.0 & 22.0 & 24.0 & 12.0 & 14.9 & 13.7 & 15.7 \\
\hline 02 & 10.9 & 13.1 & 6.4 & 9.9 & 6.8 & 8.7 & 7.6 & 7.6 & 8.4 & 12.4 & 12.9 & 16.4 \\
\hline 03 & 24.1 & 26.5 & 15.3 & 20.6 & 23.0 & 33.7 & 29.6 & 31.6 & 20.5 & 27.3 & 26.7 & 32.1 \\
\hline 04 & 33.5 & 32.5 & 40.6 & 38.3 & 14.5 & 13.1 & 16.1 & 17.4 & 26.1 & 21.8 & 22.7 & 22.0 \\
\hline 05 & 18.3 & 20.8 & 24.0 & 20.2 & 29.2 & 26.7 & 26.1 & 27.4 & 23.3 & 24.9 & 25.5 & 23.2 \\
\hline 06 & 51.8 & 53.4 & 64.6 & 58.5 & 43.7 & 39.9 & 42.2 & 44.9 & 49.4 & 46.7 & 48.2 & 45.1 \\
\hline 07 & 24.0 & 20.1 & 20.2 & 20.9 & 33.4 & 26.4 & 28.2 & 23.5 & 30.2 & 26.0 & 25.1 & 22.8 \\
\hline \multirow[t]{2}{*}{08} & 100.0 & 100.0 & 100.0 & 100.0 & 100.0 & 100.0 & 100.0 & 100.0 & 100.0 & 100.0 & 100.0 & 100.0 \\
\hline & \multicolumn{4}{|c|}{ Chile } & \multicolumn{4}{|c|}{ Colombia } & \multicolumn{4}{|c|}{ Perú } \\
\hline Sectores $b$ & 1970 & 1980 & 1990 & 1999 & 1970 & 1980 & 1990 & 1998 & 1970 & 1980 & 1990 & 1999 \\
\hline 01 & 15.9 & 10.4 & 10.8 & 11.9 & 12.3 & 11.1 & 9.7 & 9.7 & 5.7 & 9.9 & 6.2 & 4.7 \\
\hline 02 & 7.7 & 3.4 & 2.3 & 1.9 & 3.0 & 4.2 & 3.6 & 6.3 & 6.5 & 8.6 & 53 & 0.9 \\
\hline 03 & 23.6 & 13.8 & 13.1 & 13.8 & 15.3 & 15.3 & 13.2 & 16.0 & 12.1 & 18.5 & 11.5 & 5.6 \\
\hline 04 & 24.4 & 33.9 & 33.5 & 36.2 & 31.3 & 32.7 & 32.6 & 33.1 & 34.1 & 25.6 & 31.7 & 26.8 \\
\hline 05 & 21.0 & 23.7 & 25.8 & 24.9 & 18.9 & 20.1 & 24.1 & 22.3 & 19.4 & 25.0 & 26.0 & 31.1 \\
\hline 06 & 45.4 & 57.5 & 59.4 & 61.2 & 50.2 & 52.7 & 56.7 & 55.3 & 53.5 & 50.7 & 57.7 & 57.8 \\
\hline 07 & 31.0 & 28.7 & 27.5 & 25.0 & 34.5 & 32.0 & 30.1 & 28.7 & 34.4 & 30.8 & 30.8 & 36.6 \\
\hline 08 & 100.0 & 100.0 & 100.0 & 100.0 & 100.0 & 100.0 & 100.0 & 100.0 & 100.0 & 100.0 & 100.0 & 100.0 \\
\hline
\end{tabular}

Fuente: PADI (Programa de Análisis de la Dinámica Industrial), programa computacional de la Unidad de Desarrollo Industrial y Tecnológico, División de Desarrollo Productivo y Empresarial, CEPAL.

a En todos los casos se ha excluido el sector relativo a la refinación de petróleo (CIIU 353). En el caso de Chile no se ha incluido la producción industrial de cobre (CIIU 372).

b Los sectores correspondientes son:

01 Sectores con uso intensivo de ingeniería, sin automóviles (CIIU $381,382,383,385)$

02 Automóviles (CIIU 384).

03 Total sectores con uso intensivo de ingeniería $(01+02)$.

\footnotetext{
${ }^{5}$ En recientes visitas a plantas en el área de Tijuana se verificó que, mientras algunas empresas maquiladoras tienen grupos o departamentos de ingeniería de fábrica dedicados a introducir mejoras de proceso y de organización, otras - incluso competidoras cercanas de las prime-
}

04 Alimentos, bebidas y tabaco (CIIU 311, 313, 314).

05 Otros sectores con uso intensivo de recursos naturales (CIIU $331,341,351,354,355,362,369,371,372)$.

06 Total sectores con uso intensivo de recursos naturales $(04+05)$.

07 Sectores con uso intensivo de mano de obra (CIIU 321, 322, $323,324,332,342,352,356,361,390)$.

08 Total industria manufacturera.

ras - no los tienen. Obviamente, esto influye en la productividad comparada de unas y otras. Las firmas Sanyo y Samsung, por ejemplo, siguen estrategias bien diferenciadas a este respecto, pese a ser aguerridas competidoras en el mercado estadounidense de televisores. 
otro, creció significativamente en Argentina, Chile, Colombia y Perú entre 1970 y fines de los años noventa, y en Brasil a lo largo de los años ochenta y noventa. El cuadro muestra también que esto no es así en el caso de México. La industria automotriz emerge como "ganadora" en términos de participación relativa del producto industrial a lo largo de los años noventa en Argentina y Brasil ${ }^{6}$ y ya a partir de los setenta en México. Por el contrario, en ambos modelos pier- den terreno relativo las ramas productoras de bienessalario (wage goods) como calzado, textiles y muebles, y además, particularmente en Argentina y mucho más en Chile y Perú, las ramas productoras de bienes de capital, equipamiento agrícola y otros que hacen uso intensivo de servicios de ingeniería.

Complementando lo anterior, pero esta vez desde la perspectiva de las estadísticas de comercio, los cuadros 4 y 5 muestran el distinto patrón de especialización

CUADRO 4

México: Aspectos de su competitividad internacional en las importaciones mundiales, 1985-1998

\begin{tabular}{|c|c|c|c|c|}
\hline & 1985 & 1990 & 1995 & 1998 \\
\hline Participación de mercado & 1.55 & 1.29 & 1.73 & 2.24 \\
\hline Recursos naturales ${ }^{\mathrm{a}}$ & 3.59 & 2.38 & 2.05 & 2.26 \\
\hline Manufacturas basadas en recursos naturales ${ }^{\mathrm{b}}$ & 0.82 & 0.67 & 0.79 & 0.96 \\
\hline Manufacturas no basadas en recursos naturales ${ }^{\mathrm{c}}$ & 0.96 & 1.18 & 1.89 & 2.53 \\
\hline - Baja tecnología ${ }^{d}$ & 0.59 & 0.82 & 1.41 & 2.12 \\
\hline - Tecnología mediana $\mathrm{e}^{\mathrm{e}}$ & 0.98 & 1.33 & 2.22 & 2.81 \\
\hline - Alta tecnología $\mathrm{f}$ & 1.33 & 1.27 & 1.77 & 2.44 \\
\hline Otros $\mathrm{g}$ & 1.31 & 1.51 & 1.82 & 2.25 \\
\hline II. Estructura de las exportaciones & 100 & 100 & 100 & 100 \\
\hline Recursos naturales ${ }^{\mathrm{a}}$ & 53.5 & 29.3 & 15.8 & 12.4 \\
\hline Manufacturas basadas en recursos naturales ${ }^{\mathrm{b}}$ & 10.3 & 9.2 & 7.6 & 6.8 \\
\hline Manufacturas no basadas en recursos naturales ${ }^{c}$ & 33.5 & 57.5 & 73.0 & 77.2 \\
\hline - Baja tecnología & 5.4 & 10.6 & 13.6 & 15.7 \\
\hline - Tecnología mediana ${ }^{\mathrm{e}}$ & 18.1 & 32.0 & 40.0 & 38.9 \\
\hline - Alta tecnologíaf & 10.0 & 15.0 & 19.4 & 22.7 \\
\hline Otros $\mathrm{g}$ & 2.6 & 3.9 & 3.6 & 3.6 \\
\hline III. 10 exportaciones principales según contribución & 58.8 & 48.1 & 46.5 & 46.0 \\
\hline 781 Automóviles para pasajeros & 0.8 & 5.9 & 9.7 & 9.4 \\
\hline 333 Aceites de petróleo crudos & 42.0 & 19.3 & 9.3 & 7.3 \\
\hline 773 Material de distribución de electricidad & 2.4 & 4.4 & 4.8 & 4.8 \\
\hline 761 Receptores de televisión & 0.5 & 2.4 & 3.5 & 4.0 \\
\hline 764 Equipos de telecomunicaciones y partes y accesorios & 3.3 & 3.0 & 3.7 & 3.8 \\
\hline 752 Máq. para la elaboración automát. de datos y sus unidades & 0.2 & 1.7 & 2.4 & 3.8 \\
\hline 782 Vehículos automotores p/ transporte de mercancías & 0.5 & 0.6 & 2.8 & 3.6 \\
\hline 784 Partes y accesorios de vehículos automotores & 2.6 & 4.1 & 3.8 & 3.5 \\
\hline 931 Operaciones y mercancías especiales no clasificadas & 2.1 & 3.4 & 3.2 & 3.3 \\
\hline 713 Motores de combustión interna, de émbolo y sus partes & 4.4 & 3.4 & 3.2 & 2.5 \\
\hline
\end{tabular}

Fuente: Programa computacional CAN 2000. Los grupos de bienes están basados en la Clasificación Uniforme del Comercio Internacional (CUCI Rev.2).

a Contiene 45 productos básicos de sencillo procesamiento, incluye concentrados.

b Contiene 65 elementos: 35 grupos agropecuarios/forestales y 30 otros (sobre todo metales -excepto acero-, productos petroleros, cemento, vidrio, etc.).

c Contiene 120 grupos que representan la suma de ${ }^{d}+{ }^{e}+{ }^{f}$

d Contiene 44 elementos: 20 grupos de la conglomeración de textiles y prendas de vestir, más 24 otros (productos de papel, vidrio, acero, joyas).

e Contiene 58 elementos: cinco grupos de la industria automotriz, 22 de la industria de procesamiento y 31 de la industria de ingeniería.

f Contiene 18 elementos: 11 grupos de la conglomeración electrónica más siete de productos farmacéuticos, turbinas, aviones, instrumentos).

g Contiene nueve grupos no clasificados (mayormente de la sección 9).

${ }^{6}$ En Argentina y Brasil los porcentajes de participación de la actividad
automotriz en 1997 y 1998 fueron bastante mayores que en 1999. En
Argentina en 1998 ese valor era de $12.5 \%$, mientras que en Brasil en
1997 alcanzaba al $8.0 \%$. La caída de la demanda interna en esos países en los últimos años del decenio se tradujo en un notable incremento de la capacidad ociosa en ese sector y esto hace que los datos de 1999 del cuadro 3 no reflejen correctamente el importante proceso de inversión que caracterizó a la industria automotriz en los años noventa. 
Argentina: Aspectos de su competitividad internacional en las importaciones mundiales, 1985-1998

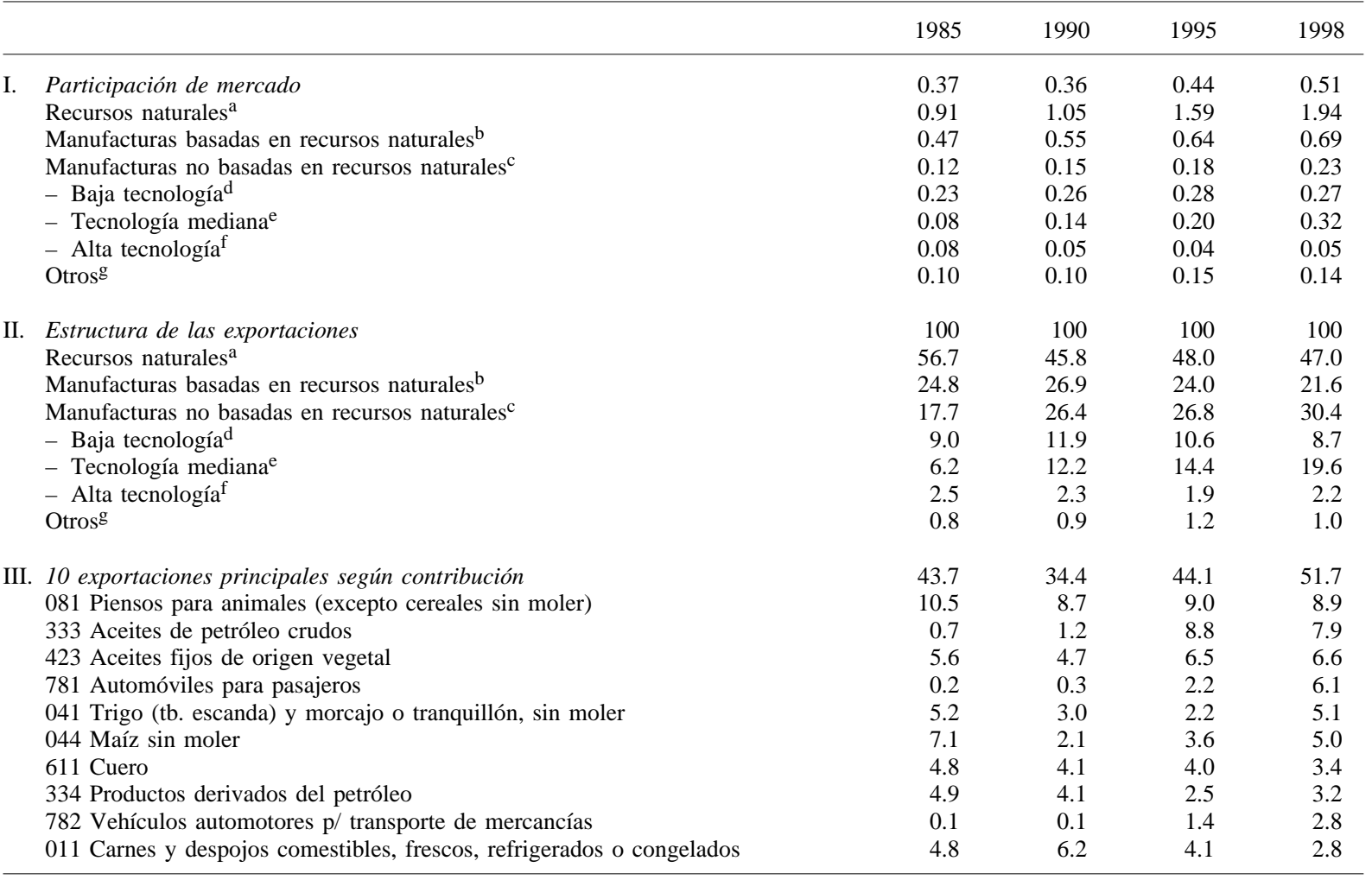

Fuente: Programa computacional CAN 2000. Los grupos de bienes están basados en la Clasificación Uniforme del Comercio Internacional (CUCI, Rev.2).

a Contiene 45 productos básicos de sencillo procesamiento, incluye concentrados.

b Contiene 65 elementos: 35 grupos agropecuarios/forestales y 30 otros (mayormente metales —excepto acero-, productos petroleros, cemento, vidrio, etc.).

c Contiene 120 grupos que representan la suma de ${ }^{d}+{ }^{e}+$.

d Contiene 44 elementos: 20 grupos de la aglomeración textiles-prendas de vestir, más 24 otros (productos de papel, vidrio y acero, joyas).

e Contiene 58 elementos: 5 grupos de la industria automotriz, 22 de la industria de procesamiento y 31 de la industria de ingeniería.

f Contiene 18 elementos: 11 grupos de la conglomeración electrónica más otros siete (productos farmacéuticos, turbinas, aviones, instrumentos).

g Contiene nueve grupos no clasificados (mayormente de la sección 9).

productiva y de comercio que México y Argentina fueron consolidando en el tiempo. México adscribió claramente a un modelo liderado por las exportaciones de sectores metalmecánicos que ensamblan bienes de consumo durables para un mercado estadounidense en rápida expansión. En cambio, Argentina — si se exceptúa su industria automotriz, que creció con fuerza en el marco de una política industrial de acuerdos gobiernoindustria-sindicatos aplicados por Argentina y Brasil a comienzos de los años noventa - tendió a concentrarse en commodities industriales, especialmente los derivados del petróleo y los aceites vegetales.
En resumen, no sólo fueron pocos los países de la región que pudieron mejorar su competitividad internacional en el decenio de 1990, sino que sólo lograron hacerlo en pocas actividades productivas. Predominaron, por un lado, las industrias maquiladoras con uso intensivo de mano de obra no calificada y dirigidas básicamente al mercado estadounidense $\mathrm{y}$, por otro, las industrias procesadoras de recursos naturales. En tanto que lo primero describe con bastante fidelidad el caso de México y de varios de los países más pequeños de América Central, lo segundo refleja el patrón de especialización productiva de los paí- 
ses del Cono Sur, típicamente Argentina, Chile, Brasil o Uruguay.

También mejoró apreciablemente la productividad y la inserción en el comercio internacional del sector automotor —y en Brasil del aeronáutico—, ${ }^{7}$ que disfrutaron de tratamiento preferencial de la autoridad económica.

Otro rasgo fundamental del proceso que estamos describiendo hace a la naturaleza de los agentes productivos que han liderado el proceso de cambios. En el modelo de maquila predomina la empresa transnacional y son pocos los grandes conglomerados internos que han logrado incorporarse satisfactoriamente al proceso como proveedores de partes o insumos intermedios (Mortimore y Peres, 2001; Garrido 2000; Kulfas 2000). ${ }^{8}$ Por el contrario, en el caso del modelo de crecimiento basado en la elaboración de recursos naturales, son los grandes grupos económicos nacionales los que adquieren un papel protagónico. En ambos escenarios la pequeña y mediana empresa de capital nacional, por un lado, y el conjunto de firmas estatales, por otro, parecen haber perdido participación relativa en años recientes. ${ }^{9}$ Nuevamente, se trata de tendencias dominantes y no de reglas excluyentes. Pero también, obviamente, es dable hallar ejemplos de firmas transnacionales que se han especializado en el procesamiento de recursos naturales, o de países en los que las PYME en su conjunto no han perdido participación en el PIB (Peres y Stumpo, 2000).

\section{La brecha relativa de productividad y la fron- tera internacional}

Comenzamos examinando el desempeño del sector manufacturero de varios países de la región en comparación con el del mismo sector en los Estados Uni-

\footnotetext{
${ }^{7}$ Sobre este tema cabe examinar con detalle el caso de Embraer, firma que en la actualidad aparece como el primer exportador brasileño de manufacturas. Dicha firma, que ha transitado por distintas etapas evolutivas en su vínculo con el sector público brasileño, da muestras de largo plazo de un notable proceso de acumulación de capacidades tecnológicas propias, que fundamentan su actual éxito exportador (véase Goldstein, 2000).

${ }^{8}$ Se da en la actualidad un interesante debate sobre el grado en que los grandes grupos económicos nacionales mexicanos han conseguido ingresar al primer "anillo" de proveedores de las ensambladoras transnacionales de vehículos, cosa que no parecen haber hecho los productores locales de autopartes de Argentina o Brasil, donde las tomas de posesión de tales empresas por grandes firmas transnacionales han sido proverbiales en los últimos años (véase Brown, 2000).

${ }^{9}$ Las cifras disponibles muestran una marcada diversidad de situaciones entre los países (véase Peres y Stumpo, 2000).
}

dos, tanto en el período 1970-1998 como en varios de sus subperíodos.

Antes de avanzar en el examen de los indicadores contenidos en el cuadro 6 es importante comprender que la economía estadounidense, que opera aquí como punto de referencia para evaluar la evolución de la productividad laboral de los países latinoamericanos, aceleró su ritmo de expansión en los años noventa por encima de su desempeño histórico.

Las cifras del cuadro 6 muestran que en 19701998 ningún país de la región alcanzó tasas de expansión de la productividad laboral en la industria superiores a las que registró el sector manufacturero de los Estados Unidos. ${ }^{10}$ Por lo tanto, no sólo la disparidad fue bastante grande en términos absolutos, sino que además la región exhibió en el largo plazo una tendencia a ampliar la brecha de productividad.

En el cuadro 7 se observa que todos los países considerados presentaron en 1998 niveles de productividad relativa (frente a los Estados Unidos) más bajos que los de 1970. Sin embargo, aquí también hay algunas diferencias entre países: la pérdida de terreno relativa es claramente menor en los casos de Brasil y, sobre todo, de Argentina. Estos dos países (junto con Uruguay hasta 1996) son los únicos que mostraron una clara tendencia a reducir la brecha de productividad a lo largo de los años noventa. Sin embargo, como ya se dijo, tampoco en estos casos el incremento de la productividad relativa permitió alcanzar los valores de comienzos de los años setenta y compensar la fuerte pérdida de terreno que se dio en los años ochenta. Además, es oportuno subrayar que, por lo menos en Argentina, la reducción de la brecha relativa de productividad en los años noventa se debió esencialmente a reestructuraciones de las empresas y a cierres de las firmas menos competitivas y no a una tendencia generalizada hacia nuevas inversiones industriales.

Esto sugiere que las reformas estructurales procompetitivas de los años noventa, pese a haber ayudado a acelerar el ritmo de transformación del aparato productivo, parecen haber contribuido muy poco, en muchos países de la región, a aproximar la productividad laboral manufacturera a la del sector manufacturero estadounidense.

El gráfico 3 muestra con claridad que la reducción de la brecha relativa de productividad laboral ha tendido a ser mayor en la rama automotriz (que disfrutó de tratamiento preferencial de la autoridad

${ }^{10}$ El país que más se acerca es Argentina, con una tasa media anual de $3.7 \%$ contra el $3.9 \%$ de los Estados Unidos. 
Producción, empleo y productividad laboral en la industria manufacturera latinoamericana, 1970-1990 y 1990-1998

(Tasas anuales medias de crecimiento)

\begin{tabular}{|c|c|c|c|c|c|c|}
\hline & \multicolumn{2}{|c|}{ Producción } & \multicolumn{2}{|c|}{ Empleo } & \multicolumn{2}{|c|}{ Productividad } \\
\hline & $1970-1990$ & 1990-1998 & $1970-1990$ & $1990-1998$ & $1970-1990$ & 1990-1998 \\
\hline Argentina & -0.3 & 5.2 & -2.3 & -2.5 & 2.0 & 7.9 \\
\hline Bolivia & 2.1 & 3.9 & 2.6 & 4.1 & -0.5 & -0.1 \\
\hline Brasil & 4.4 & 0.1 & 3.2 & -5.9 & 1.2 & 6.4 \\
\hline Chile & 1.8 & 4.8 & 0.4 & 0.3 & 1.4 & 4.4 \\
\hline Colombia & 3.6 & 1.5 & 1.8 & -1.8 & 1.8 & 3.3 \\
\hline Costa Rica & 4.8 & 4.2 & 8.0 & 1.8 & -2.9 & 2.0 \\
\hline Ecuador & 4.5 & 4.0 & 4.4 & 2.9 & 0.1 & 2.7 \\
\hline El Salvador & -0.3 & 5.8 & -1.8 & $\ldots$ & 1.8 & $\ldots$ \\
\hline Honduras & 4.6 & 4.2 & 4.9 & $\ldots$ & -0.4 & $\ldots$ \\
\hline México & 4.1 & 3.7 & 2.1 & 10 & 1.9 & 2.7 \\
\hline Panamá & 1.6 & 4.7 & 2.6 & 0.5 & -1.0 & 4.2 \\
\hline Perú & 0.7 & 4.4 & 3.1 & 2.0 & -2.4 & 3.1 \\
\hline Uruguay & 1.1 & 0.7 & 3.0 & -8.0 & -1.8 & 8.2 \\
\hline Venezuela & 3.5 & 2.7 & 3.8 & -1.0 & -0.3 & 4.8 \\
\hline EE.UU. & 3.5 & 4.3 & -0.2 & -0.2 & 3.7 & 4.5 \\
\hline
\end{tabular}

Fuente: Programa computacional PADI.

CUADRO 7

América Latina: Productividad laboral relativa de la industria frente a la del sector manufacturero de los Estados Unidos

\begin{tabular}{lrrrr}
\hline & 1970 & 1980 & 1990 & 1998 \\
\hline Argentina & 50.2 & 46.6 & 36.4 & 46.9 \\
Brasil & 35.4 & 28.3 & 21.7 & 25.0 \\
Chile & 46.2 & 42.2 & 29.5 & 29.3 \\
Colombia & 40.1 & 30.7 & 27.3 & 24.8 \\
Costa Rica $^{\mathrm{a}}$ & - & - & 15.0 & 13.8 \\
Jamaica $^{\mathrm{a}}$ & 28.0 & 16.5 & 9.3 & 8.8 \\
México $_{\text {Perúb }}^{\mathrm{b}}$ & 28.7 & 25.5 & 20.3 & 17.6 \\
Uruguay c $^{\mathrm{c}}$ & 40.4 & 30.0 & 1.9 & 11.4 \\
& 43.0 & 21.7 & 1.7 & 17.3 \\
\hline
\end{tabular}

Fuente: Programa computacional PADI.

a Datos hasta 1992. b Datos hasta 1996. c Datos hasta 1995.

económica en todos los países aquí examinados) y en las ramas procesadoras de recursos naturales, particularmente las productoras de celulosa y papel, de productos químicos y petroquímicos, y de metales no ferrosos (es decir, en aquellas ramas identificadas en el gráfico como “Otras RR.NN").

Por el contrario, muestran un peor desempeño relativo las ramas industriales que utilizan mucha mano de obra no calificada — productoras de calzado, vestuario, muebles, etc.- que no han podido hacer frente a la competencia de China. Y, sobre todo, aquellas que hacen uso intensivo de servicios de ingeniería y emprenden actividades de investigación y desarrollo (bienes de capital, industria electrónica, instrumentos científicos). Estas enfrentan el incremento masivo de importaciones facilitado por la apertura comercial externa, con las empresas de la región y claramente han ido perdiendo terreno con respecto a la frontera tecnológica internacional.

En otros términos, lo ocurrido con la brecha relativa de productividad laboral en el decenio de 1990 reafirma el hecho de que los sectores "ganadores", esto es, los que lograron aproximarse en algún grado a la frontera de la productividad internacional, fueron aquellos que resultaron privilegiados por la política industrial, que se beneficiaron de acuerdos comerciales intrarregionales o, finalmente, que adscribían al patrón de ventajas comparativas "naturales" de las economías de la región. Estos tres colectivos manufactureros conforman en la actualidad el nuevo patrón de especialización productiva. Por el contrario, claramente se van quedando atrás las industrias que hacen uso intensivo de conocimientos tecnológicos y gastan en investigación y desarrollo, y en menor medida las industrias con uso intensivo de mano de obra que producen bienessalario para el mercado interno. En tanto que a estas últimas cada vez les cuesta más competir con importaciones desde economías con mano de obra excedente, las primeras tienen el mismo problema frente a importaciones de países tecnológicamente más maduros.

En definitiva, han reducido la brecha relativa de productividad laboral i) los sectores industriales que han recibido un tratamiento preferencial de la autoridad económica; ii) las ramas maquiladoras que producen para el mercado estadounidense, y iii) las indus- 


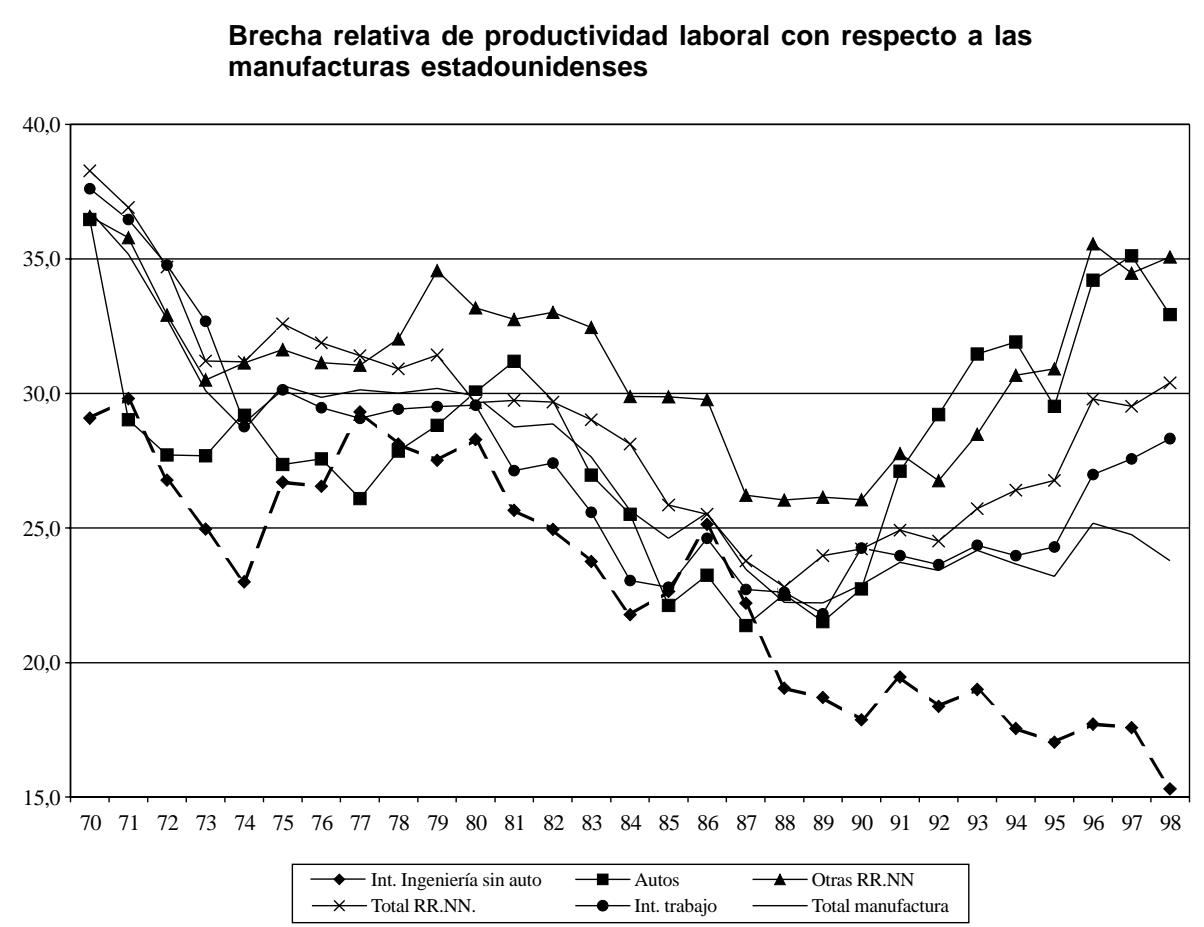

Fuente: Programa computacional PADI.

trias procesadoras de recursos naturales que albergan las ventajas comparativas estáticas de los países de la región. Por otro lado, han perdido terreno relativo internacionalmente: i) las ramas industriales que hacen uso intensivo de conocimiento, y ii) las que hacen uso intensivo de mano de obra no calificada para producir bienes-salario para el mercado interno, que en las actuales circunstancias difícilmente puede comportarse como motor de la economía interna.

¿Qué tipos de firmas tienden a predominar en los sectores "ganadores" y "perdedores"? En tanto que en el primer grupo predominan las subsidiarias locales de empresas de capital extranjero y los grandes conglomerados de capital nacional, en los sectores "perdedores" es proverbial la participación de pequeñas y medianas empresas de gestión y propiedad familiar.

El gráfico 3 muestra otro hecho de gran interés: sólo el sector automotriz se halla hoy más cerca de la frontera tecnológica internacional que veinte años atrás, a comienzos del decenio de 1980. Esto nos permite aquilatar en su verdadera y dramática magnitud la enormidad del terreno perdido a raíz de la crisis de la deuda y a lo largo de los años ochenta. Si recordamos además el papel crucial que la política industrial ha tenido en la revitalización del sector automotor, no podemos menos que reflexionar acerca de la dudosa capacidad de los mecanismos convencionales de mercado para inducir la expansión de sectores con más contenido de conocimientos tecnológicos y más valor agregado interno.

La conclusión es fuerte, sin duda, ya que cuestiona mucho del bagaje intelectual convencional de la corriente más ortodoxa de la profesión. Aun así, pensamos que los resultados expuestos transmiten una visión bastante creíble de lo ocurrido en el aparato industrial de América Latina en años recientes, y sin duda son útiles para considerar temas de política pública, cosa que haremos brevemente hacia el final de este artículo.

Por otra parte, los resultados ofrecidos hasta aquí muestran con claridad que hay grandes diferencias entre ramas de actividad y tipos de empresas en el patrón de adaptación a las nuevas reglas del juego. Es justamente esta comprobación la que nos sugiere la conveniencia de avanzar hacia los aspectos mesoeconómicos y microeconómicos de la presente transformación estructural, si deseamos comprender más a fondo lo ocurrido en los últimos años en el aparato productivo latinoamericano. Efectivamente, como veremos en la próxima sección, la transición a un modelo de organización industrial más abierto y desregulado ha estado unida a grandes cambios en lo que aquí denominamos los "regímenes" tecnológicos, institucionales y competitivos sectoriales. 


\section{III}

\section{Aspectos mesoeconómicos y microeconómicos de la transformación estructural}

\section{La evidencia empírica}

En casi todos los sectores productivos han desaparecido empresas que no pudieron adaptarse a las nuevas reglas del juego, han entrado al mercado firmas que traen consigo nuevas tecnologías de producto, de proceso y de organización del trabajo, y ha cambiado - a veces radicalmente - el marco institucional y regulatorio en que opera el sector (modificaciones en la ley de patentes de invención, en los derechos de propiedad sobre los recursos naturales, en el tratamiento fiscal, etc.). Paralelamente, ha aumentado el grado de concentración económica y también se ha acrecentado en cada mercado la presión competitiva de firmas del exterior. Las empresas han disminuido su grado de integración vertical y han avanzado hacia la producción en tiempo real, interactuando de manera muy diferente con el ámbito internacional.

Todo esto sugiere que en cada campo productivo se ha ido conformando un nuevo modelo de organización de la producción, una nueva manera de crear y distribuir el excedente económico entre los distintos agentes económicos y también entre el país y el exterior. Esto último es justamente lo que implica la globalización de la economía: que los distintos regímenes tecnológicos y competitivos sectoriales pasan a articularse más con lo externo que con lo interno.

Tomemos como ejemplo la industria siderúrgica — CIIU 371 (hierro y acero)—, en la que Argentina, Colombia y Brasil claramente se están aproximando a la frontera tecnológica internacional, en tanto que Chile y México exhiben un desempeño también dinámico, aun cuando algo menos espectacular. En otros términos, todos los países aquí estudiados lograron mejorar su posición relativa frente a los Estados Unidos en este campo a lo largo del período examinado. ¿A qué se debería este hecho? Sin duda, el fracaso estadounidense en el campo siderúrgico en todo el decenio de 1980 fue muy notorio y está bien documentado en la literatura de los años setenta y ochenta. Ese fracaso se hizo evidente en la enorme dificultad que tuvieron las empresas siderúrgicas estadounidenses para seguir el ritmo de innovación de sus competidores europeos o sudcoreanos. Pero es obvio que ésa no puede ser toda la explicación de lo ocurrido. Es la transformación del escenario interno lo que aquí nos interesa examinar.

Veamos, por ejemplo, el caso argentino. Sabemos que la industria siderúrgica de la Argentina experimentó un importante proceso de reestructuración - que incluyó la privatización de una gran acería estataldurante los decenios de 1980 y 1990. Dicho proceso involucró: i) "muertes" y "nacimientos" de empresas; ii) cambios en la trama institucional del sector, y iii) la transnacionalización de la industria o, en otros términos, su vuelco generalizado hacia el exterior, no sólo en términos de importaciones y exportaciones, sino también en términos de inversión extranjera directa y de gradual inserción en la comunidad de "jugadores globales" internacionales. Todo lo anterior se tradujo en un episodio de profunda mutación estructural y de gradual construcción de un nuevo "capitalismo competitivo" que ciertamente no existía durante los años de la industrialización sustitutiva. Es esto justamente lo que denominamos transformación de los regímenes tecnológicos y competitivos sectoriales, y lo que aquí nos interesa resaltar es la relación entre esa transformación y la competitividad internacional observada.

De las 59 plantas industriales que Argentina tenía en el campo siderúrgico en 1975 sólo 26 seguían operando en los años noventa. La planta estatal - Somisa S.A.- había sido adquirida, parcialmente desmontada y rehabilitada, por Techint S.A., uno de los dos grandes conglomerados de capital nacional que actualmente controlan los destinos de esta industria. En un rápido programa de internacionalización, este mismo grupo había adquirido, entre otras firmas, Tamsa en México y Sidor en Venezuela; al mismo tiempo formalizaba procesos de alianza estratégica con grandes grupos siderúrgicos europeos, con el fin de tomar el control de acerías estatales privatizadas por el gobierno italiano. En otros términos, Techint S.A. protagonizó en las décadas de 1980 y 1990 —más allá de los avatares de la macroeconomía argentina y de la caída que experimentó en dicho país la tasa de inversión en los años ochenta - un importante proceso de internacionalización, posicionándose como jugador global en la 
escena mundial, con negocios diversificados alrededor del planeta en el campo siderúrgico en general y en la producción de tubos sin costura en particular.

Junto con la "muerte" y "nacimiento" de empresas y el cambio en la morfología y comportamiento competitivo del sector -incluida la privatización de una acería estatal y la total desaparición del Estado como un agente importante en este mercado - se fueron produciendo transformaciones en la estructura institucional, en los mecanismos de formación de recursos humanos calificados y en la creación de nuevos conocimientos tecnológicos al interior de la industria siderúrgica, así como una marcada transformación en el patrón de ventajas comparativas y de inserción en el comercio mundial. Techint S.A. avanzó en la implantación de una nueva infraestructura de investigación y desarrollo de clase mundial, adquirió ferrocarriles y puertos, entró a participar en la producción de energía y fue consolidando gradualmente un nuevo modelo de gestión empresarial, más joven y profesionalizado que el que previamente caracterizaba al sector. Al crecer se tornó naturalmente más articulado con el exterior que con el ámbito interno. Al convertirse en un jugador global fue dejando atrás su pasado prototípico de industria sustitutiva asociada a los sectores de la defensa e incorporando paulatinamente características del capitalismo contemporáneo. Aquello pertenecía al clima internacional de la posguerra. Esto al mundo competitivo de la globalización.

Hasta aquí lo concerniente al ejemplo siderúrgico sobre el que pretendemos ahora apoyarnos para efectuar un ejercicio de teorización apreciativa. Generalizando a partir de este caso, diríamos que toda actividad productiva puede verse como un entramado de firmas, agencias — públicas y privadas-, normas y reglas de comportamiento, que en conjunto definen un régimen competitivo y tecnológico en muchos sentidos único y particular, diferente del que prevalece en otros sectores productivos. Dicho régimen responde al cuadro global de incentivos prevaleciente en la sociedad, pero también depende del patrón de inserción internacional que cada sector productivo ha desarrollado a través del tiempo, así como de la naturaleza última de los actores individuales que en él participan. Las ventajas comparativas y las formas de globalización no son exclusivamente un reflejo de los precios relativos, sino también de factores institucionales, estrategias empresariales y transformaciones tecnológicas que autónomamente va sufriendo la frontera productiva internacional. Entre las instituciones involucradas hallamos a los bancos y agentes financieros que proveen recursos tanto para gastos corrientes como para los programas de inversión de largo plazo del sector. Están también las universidades y escuelas técnicas encargadas de formar el capital humano que demanda la industria, las firmas de ingeniería que apoyan la gestión tecnológica de las empresas, las aduanas, los puertos, las firmas proveedoras de energía. De alguna forma cada uno de estos eslabones condiciona la operatoria cotidiana del sector. La trama 'almacena' un conjunto de saberes tecnológicos, marcos jurídicos y reglas de comportamiento que hacen a la mayor o menor eficiencia que el sector alcanza en un cierto momento del tiempo. Cuando decimos que la competitividad es sistémica decimos exactamente eso, que para ser eficiente un sector productivo dado debe operar en un contexto que también lo sea.

Las reformas estructurales recientes han afectado la competitividad sistémica de toda la estructura productiva a través de los cambios que han inducido en la morfología y comportamiento de los múltiples regímenes sectoriales, en su grado de articulación con lo interno y con lo externo. Cada cadena productiva, incluyendo sus firmas, sus saberes tecnológicos, sus marcos institucionales y su grado de internacionalización, tiende a cambiar, a transformarse, en función del cambio en el régimen global de incentivos que prevalece en la sociedad. Sólo una adecuada comprensión de la manera en que esto ocurre en cada contexto sectorial y nacional nos permitirá comprender las nuevas formas de funcionamiento que ha ido adquiriendo el capitalismo latinoamericano en años recientes.

\section{Principales rasgos de la transformación de los regímenes sectoriales}

\section{a) “Muerte" y "nacimiento" de empresas}

Un primer tema importante relacionado con el impacto que las reformas estructurales parecen haber tenido en casi toda actividad productiva es el de la muerte y desaparición de empresas, por un lado, y el ingreso de nuevas firmas al mercado, por otro. En efecto, al abrir la economía a la competencia externa algunas firmas se ven forzadas a abandonar el mercado ante su incapacidad para adaptarse a las nuevas reglas del juego. Eventualmente, también se produce el ingreso de nuevas firmas al mercado. Las muertes y nacimientos bien pueden ocurrir en momentos muy diferentes del tiempo, esto es, en fases muy distintas del ciclo de adaptación de cada sector al nuevo conjunto de reglas del juego. Aquí desempeñan un papel importante tanto las relaciones entre la microeconomía y la macroeconomía 
Argentina: Cambio estructural, "muertes" y "nacimientos" de empresas en la industria siderúrgica, 1975 a 1992

\begin{tabular}{|c|c|c|c|c|c|}
\hline & 1975 & 1980 & 1985 & 1990 & 1992 \\
\hline Integradas & $\begin{array}{l}\text { Alt. Horn. Zapla } \\
\text { Somisa }\end{array}$ & $\begin{array}{l}\text { Alt. Horn. Zapla } \\
\text { Somisa } \\
\text { Acindar } \\
\text { Siderca }\end{array}$ & $\begin{array}{l}\text { Alt. Horn. Zapla } \\
\text { Somisa } \\
\text { Acindar } \\
\text { Siderca }\end{array}$ & $\begin{array}{l}\text { Alt. Horn. Zapla } \\
\text { Somisa } \\
\text { Acindar } \\
\text { Siderca }\end{array}$ & $\begin{array}{l}\text { Aceros Zapla } \\
\text { Aceros Paraná } \\
\text { Acindar } \\
\text { Siderca }\end{array}$ \\
\hline Total & 2 & 4 & 4 & 4 & 4 \\
\hline Semi-integradas & $\begin{array}{l}\text { Aceros Bragado } \\
\text { Aceros Ohler } \\
\text { Acindar } \\
\text { Cura Brothers } \\
\text { Gurmendi } \\
\text { La Cantábrica } \\
\text { Mairimi\&Sinai } \\
\text { Santa Rosa } \\
\text { Siderca } \\
\text { Tamet }\end{array}$ & $\begin{array}{l}\text { Aceros Bragado } \\
\text { Gurmendi } \\
\text { La Cantábrica } \\
\text { Santa Rosa } \\
\text { Tamet }\end{array}$ & $\begin{array}{l}\text { Aceros Bragado } \\
\text { Tamet }\end{array}$ & $\begin{array}{l}\text { Aceros Bragado } \\
\text { Tamet }\end{array}$ & Aceros Bragado \\
\hline Total & 10 & 5 & 2 & 2 & 1 \\
\hline Total laminadores & 47 & 38 & 36 & 33 & 21 \\
\hline Total industria & 59 & 47 & 42 & 39 & 26 \\
\hline
\end{tabular}

Fuente: Azpiazu y Basualdo (1997).

como los cambios que, en forma paralela pero independiente, va sufriendo el cuadro institucional del sector. Una macroeconomía con alto grado de incertidumbre no estimula la instalación de plantas fabriles nuevas. Por el contrario, un escenario institucional procíclico —que favorece, por ejemplo, la inversión de largo plazo mediante un adecuado reordenamiento del mercado de capitales - puede ayudar a que la instalación de nueva capacidad ocurra más fácilmente.

En el cuadro 8 vemos que la desaparición de empresas siderúrgicas argentinas tiende a concentrarse en el conjunto de pequeñas y medianas acerías no integradas, y que ocurre en la fase temprana del ajuste macroeconómico del país. ${ }^{11}$ Los nacimientos, en cambio, parecen ocurrir en etapas posteriores del ciclo econó-

\footnotetext{
${ }^{11}$ La debilidad de la legislación antimonopolios prevaleciente en el medio local debe verse como parte del escenario institucional en que se produce la reestructuración de esta industria. Techint S.A. compró y cerró varios de los establecimientos fabriles pequeños y medianos que desaparecieron del mercado en los años ochenta. Un cuadro institucional más firme en lo que a protección de la competencia se refiere seguramente hubiera llevado a un sendero de reestructuración sectorial distinto al que finalmente hubo de seguir esta rama productiva.
}

mico, cuando ya la macroeconomía entra en una etapa de estabilización y las expectativas empresariales vuelven a privilegiar los procesos de inversión y los programas de modernización tecnológica de más largo plazo.

Mas allá del momento en que se producen las muertes y nacimientos de empresas, podemos ver que el proceso tiene un claro impacto sobre el tamaño medio de las plantas en la industria, sobre la productividad laboral y sobre el índice de concentración económica en la actividad. De manera estilizada, podemos visualizar el tema en el gráfico 4 . En el eje vertical medimos la productividad media de la rama y en el eje horizontal el tamaño medio de sus plantas. La primera distribución de productividades y tamaños describe la situación de la industria antes de la apertura de la economía, en tanto que la segunda caracteriza al sector tras la apertura externa.

Observamos que las mejoras de productividad media derivan tanto de las muertes - que, suponemos, tienden a predominar entre las firmas más chicas e ineficientes del sector- como de los nacimientos, que imaginamos asociados al ingreso en el mercado de nuevas firmas, de mayor tamaño medio y que traen 
GRAFICO 4

\section{Muerte y nacimiento de empresas y productividad media de una rama productiva}

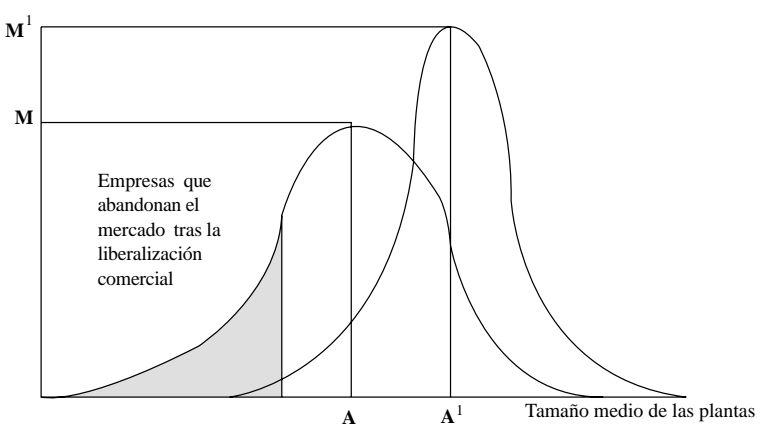

M: Promedio de productividad sectorial antes de los esfuerzos de liberalización comercial. Ml: Promedio de productividad sectorial después de la liberalización.

Fuente: Elaboración propia del autor.

consigo tecnologías productivas y de organización mucho más cercanas al "estado del arte" internacional.

El proceso de reestructuración sectorial que describimos está asociado a aumentos del grado de concentración económica, aunque probablemente también a una reducción del índice de heterogeneidad relativa entre establecimientos fabriles dentro del sector. El aumento de la concentración económica sectorial no debe verse necesariamente como un indicador de que se está acrecentando el grado de monopolización en el mercado. Recordemos que, junto con la reestructuración del sector, la apertura de la economía está acrecentando el efecto disciplinador de la competencia externa sobre las firmas locales, haciéndoles más difícil captar por medio de los precios una mayor participación en el mercado interno. Este efecto, sin embargo, seguramente difiere mucho entre ramas de actividad, dependiendo de la mayor o menor utilidad, en cada caso, de las marcas de fábrica, los derechos de patentes y otros instrumentos como medio de reforzar la capacidad de los productores locales para diferenciar sus productos de los importados. Resalta, como ejemplo extremo, el caso de la industria farmacéutica, donde el consumidor mantiene diversas formas de 'lealtad' con una cierta marca de fábrica, y donde la imperfecta información del consumidor constituye un rasgo proverbial del modelo de organización industrial del sector. Esto ha permitido a los empresarios farmacéuticos capturar rentas monopólicas aun en el marco de la apertura comercial externa (Katz, 1998). Obviamente esto no se aplica a productos menos diferenciados, más cercanos a los commodities. b) Rejuvenecimiento del parque de maquinaria y equipos y desplazamiento de la ingeniería nacional

El abaratamiento de los bienes de capital importados, merced a la apertura comercial externa, ha favorecido su utilización en reemplazo de máquinas y equipos de fabricación local, y también de servicios locales de ingeniería que normalmente se realizaban en la planta para extender la vida útil de los equipos disponibles. En otras palabras, como resultado de las reformas estructurales procompetitivas se produce, por una parte, cierto grado de rejuvenecimiento de la maquinaria y equipos disponibles en la industria y, por otro, una gradual externalización de las fuentes de progreso tecnológico que subyacen los aumentos de productividad alcanzados.

En la misma dirección, esto es, reduciendo la edad media del acervo de bienes de capital con que opera el sector y facilitando la expulsión de mano de obra calificada, han apuntado en años recientes las privatizaciones de empresas estatales (por ejemplo, en las telecomunicaciones o la energía). En varios países de la región, dentro de esos sectores, se han reducido o incluso cerrado oficinas de ingeniería y departamentos de proyectos que las firmas estatales habían creado durante los años de sustitución de importaciones. Un proceso similar parece observarse en muchas filiales locales de grandes grupos transnacionales que, al incorporarse a sistemas integrados de producción internacional operados por sus respectivas casas matrices y pasar a funcionar "en línea" con ellas, han cambiado radicalmente su patrón histórico de organización de la producción y su comportamiento tecnológico. En efecto, los esfuerzos de adaptación tecnológica parecen ser hoy menos necesarios que en el pasado; ha aumentado el componente de insumos importados que se emplean en la producción y se ha ido transitando hacia una estrategia de casi total homologación de la combinación de productos que se fabrica localmente con aquella de la casa matriz. ${ }^{12}$

En todos estos casos enfrentamos la paradoja de estar avanzando hacia diseños de producto y tecnologías de fabricación más cercanas a la frontera técnica mundial pero, al mismo tiempo, de inclinarse más hacia el ensamble de componentes importados que a la fabricación local.

En un estudio reciente, Cimoli y Katz (2001) muestran este fenómeno a través de un modelo que se

\footnotetext{
${ }^{12} \mathrm{El}$ caso de la industria automotriz resulta paradigmático en este sentido (véase Katz, 1998).
} 
sintetiza en el gráfico 5. En el primer cuadrante tenemos una función de transformación con dos factores productivos: capital nacional (KD) y capital extranjero $(\mathrm{KF})$. Las curvas en este cuadrante muestran las diversas combinaciones de maquinaria y equipo, de origen local o importado, que las firmas pueden elegir a diferentes precios relativos. La relación entre la utilización de capital extranjero y la expulsión de recursos humanos observada en las plantas productivas está representada en el cuadrante dos. En el cuadrante cuatro se describe la relación que existe entre la utilización de capital extranjero y su importación. La curva FF representa una actitud neutral de la política económica e industrial a los precios en los mercados internacionales. Un movimiento hacia el eje de las abscisas restringirá las importaciones de bienes de capital. Si la curva se desplaza en sentido opuesto, habrá mayores incentivos para la importación de dichos bienes.

Una caída del precio relativo de los bienes de capital importados con respecto a los precios de aquellos de fabricación local (por ejemplo, a raíz de una reducción de los aranceles aduaneros de importación) induce un movimiento de A hacia B. Al usar más máquinas en general se requiere menos mano de obra, pero como los equipos importados "incorporan" algunas de las habilidades de la mano de obra calificada local, su importación hará asimismo que se necesiten menos recursos humanos calificados en la planta. Por otro lado, se han hecho innecesarios algunos esfuerzos de mantenimiento que antes se llevaban a cabo para

GRAFICO 5

Abaratamiento de los bienes de capital importados y obsolescencia del capital humano local

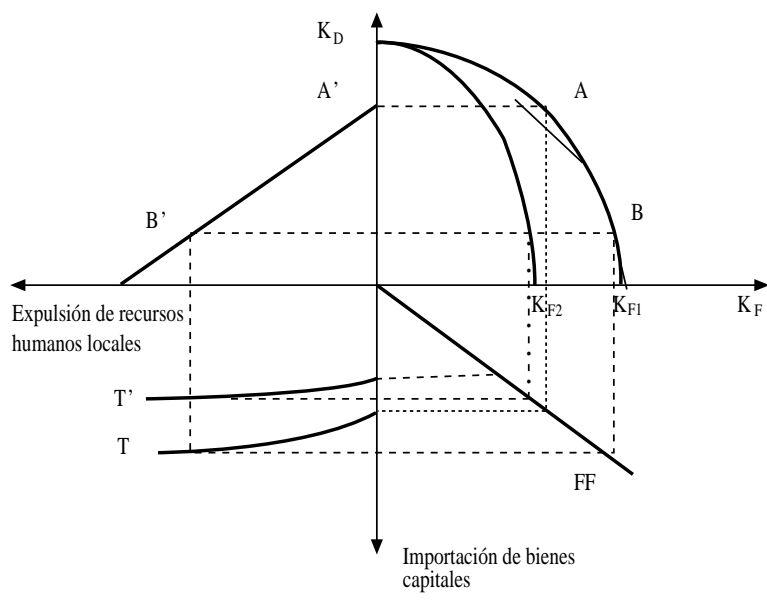

Fuente: Cimoli y Katz (2001). extender la vida útil de las máquinas, dada la mayor accesibilidad (y menor precio) de los equipos importados. Tiene menos sentido entonces mantener departamentos de ingeniería apropiados a la escala y nivel de actividad que antes se tenía, muchos de los cuales pueden ser simplemente eliminados. La curva $\mathrm{T}$ en el cuadrante tres representa la solución del modelo: una mayor importación de bienes de capital, debida a una disminución de los precios relativos, provoca una expulsión de capital humano.

El gráfico muestra también una situación en que el capital extranjero incorpora mayor contenido tecnológico, dando por resultado un desplazamiento de la curva en el primer cuadrante hacia el origen. Esto implica que el mismo nivel de producción se puede alcanzar usando menos máquinas (importadas) que antes. Si se produce más que antes —esto es, si se incorpora maquinaria importada más allá de la necesaria para fabricar el nivel inicial de producto- el desplazamiento de mano de obra calificada desde la planta será aun mayor. La curva $\mathrm{T}$ se desplazará hasta T', indicando que la misma magnitud de expulsión de recursos humanos se puede obtener con una menor importación de máquinas. Si el producto aumenta respecto a la producción inicial, la "destrucción" de capital humano local será aun mayor.

En una economía abierta el ciclo de vida útil de las máquinas tiende a ser menor, la tasa de obsolescencia mayor y el reemplazo de los equipos más rápido que en una economía más cerrada al exterior, en la que importar maquinaria es más caro (por las tarifas de importación) y más difícil (por las restricciones paraarancelarias). Aparece aquí un fenómeno nuevo e importante: al no ser la producción de conocimientos tecnológicos parte de las ventajas comparativas locales, las firmas recurrirán crecientemente a la importación de conocimientos tecnológicos 'incorporados' en los nuevos equipos que se importan, en lugar de usar máquinas y servicios de ingeniería de origen local. La acumulación de capacidades tecnológicas locales se dificultará en tales circunstancias. El caso se agrava aun más cuando, mediante las privatizaciones de empresas estatales y por la gradual transición hacia sistemas integrados de producción internacional en el conjunto de empresas extranjeras, las tareas de ingeniería y las oficinas de proyectos tienden a ser transferidas a la casa matriz. En el nuevo patrón de especialización productiva que deriva de una fusión o una privatización, la empresa local tiende a concentrarse en tareas de menor valor agregado local, más cercanas a las etapas de en- 
samble y de procesamiento primario de los recursos naturales, que a los subprocesos con mayor contenido de valor agregado local (Cimoli y Katz, 2001).

Este fenómeno tiene también consecuencias para el balance comercial y los coeficientes de importación, como veremos más adelante (apartado d).

Por otra parte, así como existe evidencia fragmentaria de fuerzas destructivas de la capacidad tecnológica interna asociadas al proceso de reestructuración sectorial hasta aquí descrito, también hay evidencia de que el mencionado proceso conlleva la aparición de procesos creativos de capacidad tecnológica interna (por ejemplo, servicios a la producción, como los de envases y embalaje, desarrollo de programas de computación, transporte y distribución en tiempo real, comercialización internacional y otros) que suponen un tránsito gradual hacia un régimen tecnológico y competitivo más sofisticado y cercano al "estado del arte" internacional.

En resumen, la reestructuración sectorial está indisolublemente asociada a un proceso de destrucción creativa tanto del capital físico como del capital humano que se vincula a un dado régimen sectorial.

\section{c) Reestructuración institucional}

El proceso hasta aquí descrito tiene un claro correlato en el ámbito de lo institucional, donde también es dable hallar distintas formas de acercamiento parcial al modelo de organización productiva de países desarrollados. La ampliación de los derechos de propiedad en el campo de los recursos naturales (algunos países han consagrado esos derechos en su texto constitucional), la desregulación de múltiples mercados (los de capital y de trabajo, entre otros), la ampliación de los derechos de propiedad intelectual, el otorgamiento por ley de trato nacional al capital extranjero son todos fragmentos de un amplio mosaico de nuevas instituciones que describen la gradual armonización del cuadro institucional en los países de la región con el de los países desarrollados.

Los cambios en la agenda internacional en esta materia comenzaron a tomar forma a mediados del decenio de 1980 y estuvieron vinculados, por una parte, a la Ley de Comercio y Aranceles Aduaneros estadounidense de 1984 y, por otra, al inicio de las negociaciones multilaterales sobre derechos de propiedad intelectual en 1986, que se plasmaron finalmente en el acuerdo TRIPs (Trade-related aspects of Intellectual Property Rights) de la Ronda Uruguay del GATT, que se firmó en Marrakesh en $1994 .{ }^{13}$ Es justamente a partir de estos años cuando se aceleró el proceso de convergencia institucional hacia el nuevo conjunto de disciplinas que hoy rigen el comercio internacional y que toman forma en los acuerdos TRIPs, TRIMs (Traderelated Investment Measures) y GATs (General Agreement on Trade in Services). En un estudio reciente, Sercovich afirma que la adhesión a la convergencia institucional es innegable. De los 109 países en desarrollo y economías en transición que han puesto en práctica reformas pro-competitivas desde los años ochenta, 75 lo hicieron a partir de 1989. Al mismo tiempo, 107 de los 134 miembros de la OMC son economías en desarrollo o en transición, en tanto que 28 -incluyendo China, la Federación Rusa y la provincia china de Taiwán- están negociando activamente su ingreso bajo cláusulas especiales. El acuerdo TRIMs establece que hasta el 2002 los países en desarrollo deberán abolir todo tipo de restricción a la inversión extranjera que afecte, entre otras cosas, a las importaciones, las exportaciones y los requisitos de contenido local (Sercovich, 1999).

En resumen, el proceso de reestructuración de los regímenes tecnológicos y competitivos sectoriales que estamos caracterizando involucra no sólo un complejo episodio de transformación de la morfología y comportamiento de cada sector productivo - por muertes y nacimientos de empresas, aumentos en el grado de concentración económica y otras vías - sino también cambios profundos en el marco institucional y regulatorio en que cada actividad funciona.

\section{d) Articulación con el exterior}

Las modificaciones al régimen global de incentivos prevalecientes en la sociedad generan cambios en los regímenes tecnológicos y competitivos sectoriales

\footnotetext{
${ }^{13} \mathrm{El}$ "Statement of Views of the European, Japanese and United States Business Communities" emitido en junio de 1988 como base preparatoria del GATT sobre derechos de propiedad intelectual afirma que: 'La inadecuada e inefectiva protección de los derechos de propiedad intelectual ha introducido fuertes distorsiones en el comercio internacional...(Dichos) derechos constituyen la base de la competitividad internacional...'. La cita fue tomada de Roffe y Tesfachew (2001), y traducida por los autores del presente artículo. Gran parte de la explicación del cambio que experimentó la agenda internacional en esos años debe buscarse en el cabildeo político llevado a cabo en Washington por la industria farmacéutica estadounidense, que veía fuertemente deteriorada su competitividad internacional a raíz de la debilidad de la legislación sobre patentes en países como Argentina, Brasil o India. Véase al respecto Olson (1991), y sobre el tema farmacéutico en general y la erosión de las ventajas comparativas de los Estados Unidos por el menor ritmo de innovación de la industria en los años setenta, véase Katz (1974).
} 
y también hacen que tales regímenes varíen radicalmente sus formas de articulación con el exterior.

Dados los cambios en los precios relativos que experimenta la economía con la apertura externa, el mayor grado de desintegración vertical que hoy tienen los procesos productivos y el papel cada vez mayor desempeñado por las grandes firmas transnacionales que operan en el marco de sistemas integrados de producción internacional (SIPI) coordinados por sus respectivas casas matrices, cabría esperar que infinidad de insumos que antes se fabricaban localmente $-\mathrm{o}$ se subcontrataban a terceros- hoy se importen, y que para poder importarlos haya que exportar más. En otros términos, parecería razonable esperar que los nuevos regímenes tecnológicos y competitivos sectoriales den pie a un mayor vuelco hacia el exterior tanto en lo que hace a importaciones como a exportaciones. También resulta razonable suponer que habrá grandes diferencias en la forma en que cada industria reestructure su patrón de articulación con el exterior. Sabemos, por ejemplo, que los sectores de industria que hacen uso intensivo de conocimiento tecnológico e investigación - como el sector farmacéutico, el electrónico o la producción de bienes de capital - han encontrado más eficiente, al reducirse la protección arancelaria, volver a comprar insumos intermedios y principios activos a sus respectivas casas matrices, en lugar de seguir fabricándolos localmente. Sabemos también que para poder importar dichos insumos intermedios muchas firmas se han visto obligadas a exportar (o conminadas a hacerlo por la autoridad económica, como en el caso de la industria automotriz).

En otros términos, el cambio en el modelo de organización de la producción - desintegración vertical一, la inserción en SIPI coordinados desde el exterior, la reducción arancelaria, la presión gubernamental o la contracción de la demanda interna han llevado a que los nuevos regímenes tecnológicos y competitivos sectoriales aparezcan como "naturalmente" más articulados que antes con el exterior. Esto trae consigo la posibilidad de que tales regímenes sean (o no) deficitarios en divisas, es decir, en su balance externo. Emerge aquí un importante nuevo tema de coordinación micro-macro: un balance global sumamente deficitario para el sector manufacturero en su conjunto corre el peligro de transformarse en un factor de potencial insustentabilidad para las reformas estructurales recientes, en la medida en que un déficit comercial elevado y crónico puede aparecer como una señal de que el tipo de cambio corriente no será sostenible en el largo plazo. Es aquí donde emergen expectativas de insustentabilidad de la macroeconomía.

Los cuadros siguientes revelan que mucho de esto efectivamente está ocurriendo, pero también indican que las diferencias entre países no son menores.

La información muestra que la transición hacia regímenes sectoriales más abiertos al comercio, tanto por el lado de las importaciones como por el de las exportaciones, ha sido mucho más marcada en México que en el de los restantes países aquí examinados (cuadro 9). El papel del Tratado de Libre Comercio de América del Norte y la presión que supone operar de manera cada vez más integrada con la mayor economía del mundo - la que además sostuvo por casi toda la década un rápido ritmo expansivo-, seguramente explican el fuerte aumento de los coeficientes tanto de importación como de exportación en el caso de México, particularmente después de la devaluación de fines de 1994. Vemos también que, más allá del fuerte aumento de ambos índices, los nuevos regímenes sectoriales mexicanos se vuelcan más hacia la exportación que hacia la importación, lo que marca una diferencia importante con los casos de Argentina, Brasil o Colombia.

A esto se debió (cuadro 10) que México lograra un saldo comercial positivo en el sector manufacturero a partir de 1999. Por el contrario, y pese a que el Mercosur ha generado aumentos importantes de comercio intrarregional, el impacto sobre el grado de apertura externa de los nuevos regímenes competitivos sectoriales de Argentina, Brasil o Colombia ha sido significativamente menor que el observado en el caso mexicano, y más fuertemente volcado hacia la importación, lo que se ha traducido en balances deficitarios de comercio manufacturero. Como lo indica nuestro razonamiento anterior, dicho balance deficitario ha estado particularmente asociado a ramas industriales con uso intensivo de conocimientos tecnológicos, servicios de ingeniería y gastos en investigación y desarrollo, que son las que fabrican bienes de capital, productos electrónicos e insumos farmoquímicos. Como argumentamos antes, en todos esos casos los nuevos regímenes competitivos sectoriales han tendido a elevar mucho más que proporcionalmente su demanda de importaciones. Su competitividad revelada claramente ha caído tras la apertura de la economía.

Los datos muestran un claro empeoramiento del balance comercial a lo largo de los años noventa, salvo para México. En Brasil y Argentina se pasó de superávit a déficit, que se incrementó hasta 1997-1998. 
CUADRO 9

América Latina (cinco países): Coeficientes de exportación e importación del sector manufacturero

\begin{tabular}{|c|c|c|c|c|c|}
\hline & 1970 & 1980 & 1990 & 1998 & 1999 \\
\hline \multicolumn{6}{|l|}{ Argentina } \\
\hline Coeficiente de exportación & 7.6 & 6.0 & 16.0 & 17.1 & 16.8 \\
\hline Coeficiente de importación & 10.3 & 11.3 & 6.8 & 30.7 & 27.6 \\
\hline \multicolumn{6}{|l|}{ Brasil } \\
\hline Coeficiente de exportación & 7.3 & 9.1 & 7.7 & 10.2 & 13.6 \\
\hline Coeficiente de importación & 8.4 & 7.1 & 4.8 & 13.0 & 15.3 \\
\hline \multicolumn{6}{|l|}{ México } \\
\hline Coeficiente de exportación & 3.4 & 2.9 & 9.5 & 42.0 & 51.7 \\
\hline Coeficiente de importación & 9.7 & 15.1 & 17.8 & 45.2 & 49.4 \\
\hline \multicolumn{6}{|l|}{ Chile } \\
\hline Coeficiente de exportación & 3.2 & 10.2 & 13.2 & 15.8 & 17.5 \\
\hline Coeficiente de importación & 21.0 & 30.1 & 34.3 & 44.0 & 35.8 \\
\hline \multicolumn{6}{|l|}{ Colombia } \\
\hline Coeficiente de exportación & 2.9 & 6.6 & 10.1 & 13.8 & \\
\hline Coeficiente de importación & 22.9 & 22.4 & 24.0 & 42.4 & \\
\hline
\end{tabular}

Fuente: Programa computacional PADI.

CUADRO 10

América Latina (cinco países): Balance comercial del sector manufacturero y de los sectores que hacen uso intensivo de tecnología

\begin{tabular}{|c|c|c|c|c|c|}
\hline \multirow[b]{2}{*}{ Países } & \multicolumn{5}{|c|}{ Balance comercial } \\
\hline & 1970 & 1980 & 1990 & 1998 & 1999 \\
\hline \multicolumn{6}{|l|}{ Argentina } \\
\hline Sectores con uso intensivo de tecnología & -519.89 & -4214.3 & -649.82 & -13050.1 & -10357.00 \\
\hline Total industria & -382.4 & -4237.21 & 4592.41 & -13107.8 & -9431.69 \\
\hline \multicolumn{6}{|l|}{ Brasil } \\
\hline Sectores con uso intensivo de tecnología & -1051.16 & -2136.85 & -947.89 & -15855.5 & -12194.50 \\
\hline Total industria & -291.13 & 3478.45 & 9252.51 & -10918.3 & -4607.14 \\
\hline \multicolumn{6}{|l|}{ México } \\
\hline Sectores con uso intensivo de tecnología & -1201.92 & -8237.65 & -6800.07 & 5894.14 & 22143.48 \\
\hline Total industria & -1404.33 & -13193.1 & -11912.3 & -7929.67 & 6327.72 \\
\hline \multicolumn{6}{|l|}{ Chile } \\
\hline Sectores con uso intensivo de tecnología & -437.74 & -1804.3 & -3272.27 & -7664.89 & -5188.14 \\
\hline Total industria & -643.29 & -2357.18 & -3439.62 & -9470.48 & -5790.67 \\
\hline \multicolumn{6}{|l|}{ Colombia } \\
\hline Sectores con uso intensivo de tecnología & -419.61 & -1793.25 & -2205.66 & -6105.21 & -3876.11 \\
\hline Total industria & -677.89 & -2626.78 & -2810.82 & -8912.3 & -5403.23 \\
\hline
\end{tabular}

Fuente: Programa computacional PADI.

A partir de allí volvemos a observar cierta mejora en las cuentas externas, pero más por caídas en la demanda de importaciones (Argentina, Chile y Colombia) y por cambios de precios relativos (devaluación) en Brasil, que por una rápida expansión de la corriente exportadora. En estos cuatro países, en 1999 las importaciones bajaron con respecto al año anterior (en valores nominales la caída fue de $19 \%$ en Argentina,
$17 \%$ en Brasil, $25 \%$ en Chile y $28 \%$ en Colombia), en tanto que las exportaciones de Argentina, Brasil y Colombia también descendieron en valores nominales, mientras se incrementaban levemente las de Chile.

En México, la situación del balance comercial es diferente. Por primera vez en el período que estamos considerando (1970-1999), el balance de comercio mexicano fue positivo, lo que se debió esencialmente 
América Latina (cinco países): Coeficientes de importación

\begin{tabular}{|c|c|c|c|c|c|c|c|c|c|c|c|c|c|}
\hline \multirow[b]{2}{*}{ Sectores ${ }^{a}$} & \multicolumn{5}{|c|}{ Argentina } & \multicolumn{4}{|c|}{ Brasil } & \multicolumn{4}{|c|}{ México } \\
\hline & 1970 & 1980 & 1990 & 1998 & 1999 & 1970 & 1980 & 1990 & 1999 & 1970 & 1980 & 1990 & 1999 \\
\hline 01 & 28.3 & 33.3 & 21.4 & 126.0 & 112.8 & 22.9 & 13.6 & 10.1 & 36.6 & 26.1 & 32.3 & 42.9 & 105.5 \\
\hline 02 & 5.3 & 11.7 & 6.1 & 43.7 & 33.3 & 11.8 & 9.3 & 3.6 & 22.2 & 25.2 & 25.6 & 23.3 & 32.7 \\
\hline 03 & 17.8 & 23.5 & 14.8 & 77.0 & 65.5 & 19.0 & 12.3 & 8.0 & 31.6 & 25.8 & 29.8 & 34.2 & 72.7 \\
\hline 04 & 0.8 & 1.6 & 0.4 & 3.2 & 3.0 & 1.5 & 1.8 & 2.2 & 3.0 & 1.4 & 5.5 & 7.4 & 7.3 \\
\hline 05 & 23.9 & 14.9 & 10.6 & 28.8 & 27.0 & 12.3 & 9.6 & 5.5 & 14.3 & 10.7 & 19.0 & 17.5 & 52.9 \\
\hline 06 & 10.0 & 6.9 & 5.0 & 13.7 & 12.9 & 6.7 & 6.7 & 4.1 & 8.9 & 5.1 & 11.7 & 12.1 & 26.4 \\
\hline 07 & 3.8 & 7.5 & 4.0 & 26.4 & 27.4 & 2.2 & 1.7 & 2.1 & 9.2 & $4-0$ & 4.5 & 9.4 & 43.0 \\
\hline \multirow[t]{2}{*}{08} & 10.3 & 11.3 & 6.8 & 30.7 & 27.6 & 8.4 & 7.1 & 4.8 & 15.3 & $9-7$ & 15.1 & 17.8 & 49.4 \\
\hline & \multicolumn{5}{|c|}{ Chile } & \multicolumn{4}{|c|}{ Colombia } & & & & \\
\hline Sectores ${ }^{\text {a }}$ & 1970 & 1980 & 1990 & 1998 & 1999 & 1970 & 1980 & 1990 & 1998 & & & & \\
\hline 01 & 65.9 & 102.3 & 151.3 & 187.0 & 157.3 & 79.0 & 82.2 & 97.9 & 158.3 & & & & \\
\hline 02 & 47.5 & 133.4 & 151.7 & 211.0 & 142.6 & 112.4 & 64.1 & 44.2 & 98.7 & & & & \\
\hline 03 & 59.6 & 111.8 & 151.4 & 192.3 & 154.3 & 88.8 & 75.6 & 76.9 & 136.2 & & & & \\
\hline 04 & 6.7 & 10.4 & 3.8 & 7.2 & 6.7 & 2.5 & 4.7 & 2.5 & 8.8 & & & & \\
\hline 05 & 20.9 & 24.3 & 32.4 & 33.6 & 28.1 & 40.4 & 36.8 & 42.1 & 56.9 & & & & \\
\hline 06 & 12.9 & 15.7 & 15.4 & 18.1 & 15.4 & 15.5 & 16.4 & 18.6 & 27.5 & & & & \\
\hline 07 & 6.8 & 17.4 & 16.3 & 34.2 & 33.0 & 6.3 & 5.8 & 6.5 & 20.6 & & & & \\
\hline 08 & 21.0 & 30.1 & 34.3 & 44.0 & 35.8 & 22.9 & 22.4 & 24.0 & 42.4 & & & & \\
\hline
\end{tabular}

Fuente: Programa computacional PADI.

a Los sectores correspondientes son:

01 Sectores con uso intensivo de ingeniería, excluidos los automóviles (CIIU 381, 382, 383, 385).

02 Automóviles (CIIU 384).

03 Total sectores con uso intensivo de ingeniería $(01+02)$.

04 Alimentos, bebidas y tabaco (CIIU 311, 313, 314).

05 Otros sectores con uso intensivo de recursos naturales (CIIU 331, 341, 351, 354, 355, 362, 369, 371, 372).

06 Total sectores con uso intensivo de recursos naturales $(04+05)$.

07 Sectores con uso intensivo de mano de obra (CIIU 321, 322, 323, 324, 332, 342, 352, 356, 361, 390).

08 Total industria manufacturera.

a que el fuerte aumento de las exportaciones superó el también fuerte incremento de las importaciones.

Un análisis más desagregado de los coeficientes de importación (cuadro 11) nos permite observar el impresionante incremento de los mismos en los años noventa, concentrado sobre todo en los sectores productores de bienes de capital y de bienes de consumo duradero (electrónica, bienes informáticos, electrodomésticos). La caída de la demanda interna a finales de la década redujo dichos coeficientes en 1999, y disminuyó por lo tanto el déficit del balance comercial en Argentina, Chile, Colombia y Brasil; por el contrario, en México el mejoramiento del saldo comercial respondió más bien a un incremento de la capacidad exportadora.
Este parece ser otro rasgo importante del nuevo modelo económico (con la excepción de México, que, como se dijo, pasó por un proceso diferente de cambio de su estructura productiva y de integración a otros circuitos comerciales): las fases de crecimiento de la demanda interna llevan a déficit cada vez mayores de la cuenta comercial (a veces de dudosa sostenibilidad) que llegan a reducirse (sin ser eliminados) sólo en períodos de recesión, por la incapacidad de la estructura productiva (que ha pasado por los procesos de reestructuración y "destrucción" de los años ochenta y noventa) para competir con las importaciones y generar flujos de exportaciones, salvo en unas pocas ramas vinculadas con el procesamiento de recursos naturales. 


\section{IV}

\section{Conclusiones}

La transición desde un paradigma de desarrollo endodirigido, liderado por el Estado, hacia otro más abierto y desregulado - en el que la "mano invisible" desempeña un papel protagónico como guía de la asignación de recursos- ha hecho surgir en los diversos países de la región nuevos patrones de especialización productiva y de inserción en los mercados mundiales de bienes y servicios. Esto en el marco de un episodio de largo plazo de "destrucción creativa" de naturaleza schumpeteriana, en el cual un determinado modelo de organización de la producción y de comportamiento institucional y tecnológico fue desplazado gradualmente por otro, mediante la acción conjunta e interdependiente de fuerzas económicas, tecnológicas e institucionales.

En las páginas anteriores se ha mostrado cómo efectivamente se han ido consolidando grandes cambios en el patrón de especialización productiva y de inserción en las corrientes mundiales de comercio, conformándose dos grandes modelos dominantes en el conjunto de la región. Por un lado, el modelo de maquila, centrado en México y varios países más pequeños de América Central, y, por otro, el modelo basado en el procesamiento de recursos naturales que caracteriza a varias de las economías del Cono Sur de la región, en especial Argentina, Brasil, Chile y Uruguay, y varios países andinos, como Colombia y Perú.

Está claro que, para entender este proceso de transformación, tenemos que dejar el ámbito estrictamente macroeconómico y descender al ámbito de lo mesoeconómico y lo microeconómico, ya que es allí donde se han materializado los cambios de años recientes en los modelos dominantes de organización productiva de los distintos países de la región. Ha cambiado la participación relativa de los diversos tipos de empresas - filiales locales de grandes grupos trasnacionales, conglomerados de capital nacional, pequeñas y medianas empresas de propiedad y gestión familiarasí como también las fuentes de crecimiento económico que subyacen cada actividad productiva. Asimismo, se han ido consolidando nuevos patrones de comportamiento microeconómico en los cuales los bienes de capital e insumos intermedios importados han ido desplazando tanto a la producción interna de ellos como a los esfuerzos tecnológicos locales asociados a su fa- bricación. Así, se ha ido conformando un nuevo modelo de organización de la producción más articulado con el exterior que en el pasado.

Sin embargo, el crecimiento liderado por las exportaciones no parece ser tan automático como a veces suponemos en los debates contemporáneos. El análisis realizado ha puesto claramente en evidencia que el proceso de crecimiento y reestructuración del aparato productivo de los años noventa está planteando una serie de problemas bastante complejos que, de no ser resueltos, pueden comprometer seriamente las posibilidades de crecimiento de los países de la región.

En este sentido, cabe subrayar que de estos países no sólo son pocos los que lograron mejorar su competitividad internacional en el decenio de 1990, sino que también fueron pocas las actividades productivas en que lo hicieron. Predominaron entre éstas, por un lado, las industrias maquiladoras con uso intensivo de mano de obra no calificada y dirigidas básicamente al mercado estadounidense $y$, por otro, las industrias procesadoras de recursos naturales.

Esto se refleja también en el débil desempeño de la productividad laboral relativa en los países de la región, en comparación con la evolución de esa productividad en los Estados Unidos: aunque casi todos los primeros exhibieron un incremento importante de la productividad laboral absoluta del sector manufacturero en el decenio de 1990, sólo en muy pocos casos (esencialmente Argentina y Brasil) ese incremento superó el de la productividad estadounidense y, lo que es peor, en ningún caso se llegó a los niveles de productividad relativa de comienzos de los años setenta.

Estos aspectos de debilidad del nuevo modelo económico se reflejan claramente en los déficit del balance comercial (que se deben principalmente a los rubros relacionados con las ramas de mayor complejidad tecnológica). Tales déficit son crecientes, como hemos visto, a menos que la economía entre en una fase de recesión.

La complejidad de los problemas observados nos llevan a concluir que es mucho más lo que debe hacerse hoy en materia de política económica. Esto ya comienza a ser percibido por varios países de la región que en los últimos años han ido abandonando 
gradualmente los cánones estrictos de la ortodoxia y están explorando una nueva agenda de acciones de política pública con el fin de mejorar su desempeño de largo plazo.

Creemos que, sobre la base del diagnóstico contenido en las páginas anteriores, es necesario plantear algunas preguntas de política económica sobre cuatro aspectos específicos: i) marcos regulatorios y protección al consumidor; ii) políticas de competencia; iii) medidas de fomento productivo y desarrollo tecnológico, y iv) sinergias y externalidades en ámbitos locales. En cada uno de estos aspectos podemos identificar fallas de mercado, asimetrías de información, explotación de posiciones dominantes de mercado y otras deficiencias, lo que nos lleva a pensar en la conveniencia de adoptar medidas de reingeniería institucional y políticas de construcción de mercados y de ventajas comparativas dinámicas basadas en el conocimiento, que favorecerían una más eficiente (y equitativa) transición hacia economías más abiertas y competitivas. Cada uno de estos temas demandaría un extenso análisis que no es del caso efectuar en esta oportunidad.
Amstrong, M., S. Cowan y J. Vickers (1994): Regulatory Reform, Economic Analysis and the British Experience, Cambridge, Massachusetts, The MIT Press.

Azpiazu, D. y J. Basualdo (1997): La internacionalización reconsiderada: el caso de Siderar, Buenos Aires, julio, mimeo.

Brown, F. (2000): La industria automotriz mexicana: reestructuración reciente y perspectivas, Santiago de Chile, CEPAL, mimeo, marzo.

Buitelaar, R., R. Padilla y R. Urrutia (1999), Centroamérica, México y República Dominicana: maquila y transformación productiva, Cuadernos de la CEPAL, $\mathrm{N}^{\circ}$ 85, Santiago de Chile, CEPAL.

Caballero, R. y H. Hammour (1996): On the timing and efficiency of creative destruction, Quarterly Journal of Economics, vol. 111, $N^{\circ} 3$, Cambridge, Massachusetts, The MIT Press.

Campos, R. y J.A. Nicolau (2000): Arranjo produtivo textil-vestuario do vale do Itajais, Nota técnica, Arranjos Produtivos Locais e as Novas Politicas de Desenvolvimento, Rio de Janeiro, mimeo.

Cassiolato, J. y H. Lastres (2000a): Local systems of innovation in Mercosur countries, Industry and Innovation, Vol. 7, $\mathrm{N}^{\circ} 1$. Reproducido en Arranjos Produtivos Locais e as Novas Politicas de Desenvolvimento, Rio de Janeiro, mimeo.

(2000b): Novas politicas industriais descentralizadas em paises seleccionados, en Instituto de Pesquisa Economica Aplicada (IPEA), Relatorio de Pesquisa, Rio de Janeiro, (IE)/ Universidad Federal de Rio de Janeiro.

CEPAL (2000): Equidad, desarrollo y ciudadanía, LC/G.2071, Santiago de Chile.

Cimoli, M. y J. Katz (2001): Reformas estructurales, brechas tecnológicas y el pensamiento del Dr. Prebisch. Este documento fue presentado en el seminario internacional "La teoría del desarrollo en los albores del siglo XXI", evento conmemorativo del centenario del nacimiento de Raúl Prebisch (CEPAL, Santiago de Chile, 28 y 29 de agosto de 2001).

Confederación Nacional de la Industria (1997): Politicas estaduais de apoio a industria, Rio Grande do Sul, Secretaria da Coordenação e Planejamento.

David, P. (1994), Why are institutions the "carriers of history". Path dependence and the evolution of conventions, organizations and institutions, Structural Change and Economic Dynamic, vol. $5, \mathrm{~N}^{\circ} 2$.

Dussel, P. E. (2000a): Polarizing Mexico: the impact of liberalization strategy, Londres, Lynne Riener.

(2000b): El programa de promoción sectorial (Prosec). Implicaciones para las importaciones temporales y el resto del aparato productivo mexicano, octubre, mimeo.

Fernández Arias, E., R. Hausmann y E. Stein (2001), Courting FDI: is competition bad?, Santiago de Chile, enero, mimeo.
Ffrench-Davis, Ricardo (1999): Entre el neoliberalismo y el crecimiento con equidad: Tres décadas de política económica en Chile, Dolmen Ediciones, Santiago.

Garrido, C. (2000); Fusiones y adquisiciones transfronterizas en México durante los noventa, México, D.F., Universidad Autónoma Metropolitana (UAM).

Gerber, J. (2000): Uncertainty and growth in the maquiladora industry, San Diego, San Diego State University, Departamento de Economía, mimeo.

Goldstein, A. (2000): From national champion to global player: explaining the success of Embraer, París, Organización de Cooperación y Desarrollo Económicos (OCDE), mimeo.

Gordon, R. (1999): Has the new economy rendered the productivity slowdown obsolete?, Cambridge, Massachusetts, Oficina Nacional de Investigaciones Económicas (NBER), junio.

Held, G. (1999): Políticas de crédito para empresas de menor tamaño con bancos de segundo piso: experiencias recientes en Chile, Colombia y Costa Rica, serie Financiamiento del desarrollo, No 84, Santiago de Chile, CEPAL.

Katz, J. (1974): Oligopolio, firmas nacionales y empresas multinacionales. La industria farmacéutica argentina, Buenos Aires, Siglo XXI.

(1996): Apertura y desregulación en el mercado de medicamentos, Buenos Aires, CEPAL/Centro Internacional de Investigaciones para el Desarrollo/Alianza Editorial.

(1997): Aprendizaje y desarrollo de capacidades tecnológicas domésticas en la etapa de la sustitución de importaciones, Buenos Aires, Pulso/Socma.

(1998): Pulso, Buenos Aires.

(2000): Reformas estructurales, productividad y conducto tecnológica en América Latina, Santiago de Chile, CEPAL/ Fondo de Cultura Económica.

Kulfas, M. (2000): El impacto del proceso de fusiones y adquisiciones en la Argentina sobre el mapa de las grandes empresas. Factores determinantes y transformaciones en el universo de grandes empresas de capital local, Buenos Aires, Oficina de la CEPAL en Buenos Aires.

Miranda, J.C. (2000): Apertura comercial, reestructuraçao industrial e exportaçoes brasileiras. Avaliação de potencial exportador das 500 maiores empresas industriais brasileiras, Proyecto CLA/99-1671, Rio de Janeiro, Universidad General de Rio de Janeiro, septiembre.

Moguillansky, G., y R. Bielschowsky (2000): Inversión y reformas económicas en América Latina, Santiago de Chile, Fondo de Cultura Económica/CEPAL

Mortimore, M., y W. Peres (2001): La competitividad internacional de América Latina y el Caribe. Las dinámicas microeconómicas y sectoriales, Santiago de Chile, CEPAL. 
Naim, M. y J.S. Tulchin (1999): Competition policy, deregulation and modernization in Latin America, Londres, Lynne Riener.

Nelson, Richard (1997): How new is new growth theory?, Nueva York, Challenge.

Nelson, Roy (s/f): Intel site selection decision in Latin America, Glendale, Arizona, Thunderbird University, Department of International Studies.

Ocampo, J.A., (2001): Retomar la agenda del desarrollo, Santiago de Chile, CEPAL.

Olson, M. (1991): Political influence and the development of US regulatory policy: the 1984 drug legislation. CERP Discussion Paper 249, Stanford, California, Centro de Investigación sobre Políticas Económicas.

Patel, S.J., P. Roffe y A.Yusuf (2001): International Technology Transfer, Londres, Kluwer Law International.

Peres, W. y G. Stumpo (2000): Small and medium size industrial enterprises in Latin America and the Caribbean under the new economic model, World Development, vol. 28, N 9, Oxford, Reino Unido, Pergamon Press, Ltd.

Roffe, P., y T. Tesfachew (2001): The unfinished agenda, en S.J. Patel, P. Roffe y A. Yusuf. International Technology Transfer, Londres, Kluwer Law International.

Projeto de Pesquisa Arranjos Produtivos Locais (2000): $\mathrm{N}^{\circ} 18$, Rio de Janeiro, septiembre, mimeo.
Rubens, J., N. Cano y A.L. Goncalves da Silva (2000): Arranjo Produtivo de Telecomunicacoes de Campinas, Nota técnica, $\mathrm{N}^{\circ} 16$, Rio de Janeiro, Projeto de Pesquisa Arranjos e Sistemas Produtivos Locais, septiembre, mimeo.

Schmitz, H. (1995): Small shoemakers and Fordist giants: tale of a supercluster, World Development, vol. 23, $\mathrm{N}^{\circ} 1$, Oxford, Reino Unido, Pergamon Press, Ltd.

Sercovich, F. (1999): Competition and the World Economy, Cheltenham, Reino Unido, Edward Elgar/ Organización de las Naciones Unidas para el Desarrollo Industrial (ONUDI).

Stallings, B. y W. Peres (2000): Crecimiento, empleo y equidad: el impacto de las reformas económicas en América Latina y el Caribe, Santiago de Chile, CEPAL/Fondo de Cultura Económica.

Tavares de Araujo, J. (2000), Competition policy and EU-Mercosur trade negotiations, mimeo.

Vargas, M.A. y R.M. Alievi (2000): Arranjo produtivo coureirocalcadista do vale dos Sinos, Nota técnica $\mathrm{N}^{\circ} 19$, Rio de Janeiro, Projeto de Pesquisa Arranjos e Sistema Produtivos Locais, septiembre, mimeo.

Weller, J. (2000): Reformas económicas, crecimiento y empleo: los mercados de trabajo en América Latina y el Caribe, Santiago de Chile, CEPAL/Fondo de Cultura Económica.

World Development (2000): vol. 28, N 9, Oxford, Reino Unido, Pergamon Press, Ltd. 